\title{
CFD Analysis of Urban Canopy Flows Employing the V2F Model: Impact of Different Aspect Ratios and Relative Heights
}

\author{
Fabio Nardecchia, ${ }^{1}$ Annalisa Di Bernardino, ${ }^{2}$ Francesca Pagliaro, ${ }^{1}$ Paolo Monti $\mathbb{D}^{2}$, \\ Giovanni Leuzzi, ${ }^{2}$ and Luca Gugliermetti ${ }^{1}$ \\ ${ }^{1}$ Sapienza University of Rome, DAEEE, Via Eudossiana 18, Rome 00184, Italy \\ ${ }^{2}$ Sapienza University of Rome, DICEA, Via Eudossiana 18, Rome 00184, Italy \\ Correspondence should be addressed to Paolo Monti; paolo.monti@uniroma1.it
}

Received 19 March 2018; Accepted 2 July 2018; Published 29 July 2018

Academic Editor: Jorge E. Gonzalez

Copyright ( 92018 Fabio Nardecchia et al. This is an open access article distributed under the Creative Commons Attribution License, which permits unrestricted use, distribution, and reproduction in any medium, provided the original work is properly cited.

\begin{abstract}
Computational fluid dynamics (CFD) is currently used in the environmental field to simulate flow and dispersion of pollutants around buildings. However, the closure assumptions of the turbulence usually employed in CFD codes are not always physically based and adequate for all the flow regimes relating to practical applications. The starting point of this work is the performance assessment of the V2F (i.e., $\overline{v^{2}}-f$ ) model implemented in Ansys Fluent for simulating the flow field in an idealized array of twodimensional canyons. The V2F model has been used in the past to predict low-speed and wall-bounded flows, but it has never been used to simulate airflows in urban street canyons. The numerical results are validated against experimental data collected in the water channel and compared with other turbulence models incorporated in Ansys Fluent (i.e., variations of both $k-\varepsilon$ and $k-\omega$ models and the Reynolds stress model). The results show that the V2F model provides the best prediction of the flow field for two flow regimes commonly found in urban canopies. The V2F model is also employed to quantify the air-exchange rate (ACH) for a series of two-dimensional building arrangements, such as step-up and step-down configurations, having different aspect ratios and relative heights of the buildings. The results show a clear dependence of the ACH on the latter two parameters and highlight the role played by the turbulence in the exchange of air mass, particularly important for the step-down configurations, when the ventilation associated with the mean flow is generally poor.
\end{abstract}

\section{Introduction}

The continuous growth of large cities occurred in the last decades has prompted the scientific community towards the understanding of the urban environment $[1,2]$. Great attention has been paid especially in predicting the flow field within and outside the urban street canyon, which is the space delimited by the street and the facades of the surrounding buildings. Knowledge on wind and temperature distributions within the street canyon is crucial, for example, in the design of the urban geometry with the aim of achieving an energy-optimized architecture of the city [3-5] as well as determining the concentration of pollutants emitted at the street level by vehicular traffic [6-8].

One of the parameters that mostly influence the gross features of the flow over urban canopies is the aspect ratio,
$\mathrm{AR}$, which is defined as the ratio between the average height of the buildings, $H$, and the spacing, $W$, between two consecutive buildings. Oke [3] introduced three kinds of flow regimes as a function of AR: isolated obstacle, wake interference, and skimming flow. In the isolated-obstacle regime $(\mathrm{AR}<0.4)$, the flow around each building is not affected by disturbances coming from other obstacles. In the wake-interference flow $(0.4<\mathrm{AR}<0.67)$, two counterrotating vortices form within the canyon, and the wake of each building interacts with the subsequent building. The skimming flow $(A R>0.67)$ corresponds to narrow urban canyons, where the wind circulation is characterized by a vortex that occupies a large part of the canyon. Besides the three flow regimes defined by Oke, there is a fourth flow pattern, the multivortex flow regime $(\mathrm{AR}>1.54)$, which is a variant of the skimming flow [9]. Another important 
parameter influencing the street canyon is the relative height of the buildings, $H_{2} / H_{1}$, where $H_{1}$ and $H_{2}$ are the heights of the leeward and the windward buildings, respectively.

Thanks to the increasing computational power of computers, computational fluid dynamics (CFD) has recently supported laboratory and field experiments, improving the knowledge of street-canyon flows. Much effort has been done in recent years to analyze urban canopy flows by means of CFD, often using Reynolds-averaged NavierStokes (RANS) simulations of two-dimensional (2D) arrays of buildings. The interest of the scientific community for such a simplified building arrangement is justified by the fact that the 2D array can be considered as an archetype for more complex geometries [10-13]. Huang et al. [14] carried out 2D simulations to investigate the effect of wedge-shaped roofs on the flow in an urban street canyon and found that they have significant influence on the vortex structure and pollutant distribution pattern. Memon et al. [15] analyzed heating in $2 \mathrm{D}$ isolated street canyons applying the RNG $k-\varepsilon$ model (here, $k$ is the turbulent kinetic energy, while $\varepsilon$ is its rate of dissipation). Those authors compared their results with wind-tunnel data and showed that the nighttime and daytime air temperature difference between urban and rural areas closely resembles each other. Murena and Mele [16] analyzed an ideal deep street canyon with 2D unsteady RANS simulations using the shear stress transport (SST) $k-\omega$ model. They observed that short-time variations of wind velocity can greatly influence the mass transfer rate between the canyon and the overlying boundary layer. Allegrini et al. [17] carried out 2D steady RANS simulations with different near-wall treatments in order to validate numerical results for buoyant flows in urban street canyons by comparison with wind-tunnel measurements. They compared the results of different turbulence models (STD $k$ - $\varepsilon$, realizable $k-\varepsilon, k-\omega$, Spalart-Allmaras, and Reynolds stress model (RSM)), showing a better agreement of the STD $k$ - $\varepsilon$ model with the NEWFs (nonequilibrium wall functions) than the LRNM (low-Reynolds number modeling). Ho et al. [18] studied idealized 2D urban street canyons of different ARs and urban boundary-layer depths using the RNG $k-\varepsilon$ model. They found that the atmospheric turbulence contributes most to street-level ventilation because the turbulent component of the air-exchange rate $(\mathrm{ACH})$ dominates the transport process. Xie et al. [19] investigated the impact of the urban street layout on the local atmospheric environment through numerical simulation and wind-tunnel experiments. The authors found that the vortex structure in the canyon and, consequently, the street layout strongly influence the wind field and the pollutant dispersion in the canopy.

A well-known CFD approach alternative to RANS simulation is the large eddy simulation (LES), which explicitly resolves the larger structures of the turbulence, while it models the finer ones by adopting suitable closure assumptions [20-22]. It is believed that the RANS approach provides reasonable accurate predictions of mean flow quantities and that it is still an appropriate methodology considering the low CPU cost. However, in some applications such as the analysis of transient features of the flow like vortex shedding in the wake, LES performs generally better than RANS simulation [6]. In any case, LES resolves the large-scale turbulent eddies, which are $3 \mathrm{D}$ by nature. Therefore, since in this work a $2 \mathrm{D}$ simulation has been used, the most suitable CFD approach is the RANS one.

Based on the previous literature, the $k-\varepsilon$ turbulence model appears to be the most widely employed one in CFD simulations of urban canopy flows. However, uncertainties still exist regarding the capability of CFD codes in simulating velocity and turbulence fields in different flow regimes. For this reason, a comparison between numerical results obtained through Ansys Fluent v.14.5 [23] and experimental data taken in the water channel has been carried out in this work. In addition to the most known turbulence models, the comparison has also taken into account the V2F model, based on the $k-\varepsilon-\overline{v^{2}}$ closure developed by Durbin [24]. The V2F model is similar to the STD $k$ - $\varepsilon$ model but includes an additional transport equation that models the velocity scale, $\overline{v^{2}}$, and its source term, $f$ [25]. Since the V2F model incorporates both near-wall turbulence anisotropies and nonlocal pressure-strain effects, it is usually employed for low-speed and wall-bounded flows. This implies that wall functions are not required, and consequently, lower computational costs are needed. The V2F model has been developed for attached or mildly separated boundary layers and used mainly for studying three-dimensional (3D) boundary layers $[26,27]$ and heat transfer problems in jet impingement [28-30] and in ribbed-channel flows [31, 32], subsonic and transonic flows for aerospace applications $[33,34]$, and flow physical phenomena in enclosed environments [35-37]. To the best of our knowledge, this paper is the first one to deal with numerical simulations of $2 \mathrm{D}$ street canyons by means of the V2F model. Here, the effectiveness of the V2F model in predicting the flow field for two typical building arrangements $(A R=0.5$ and 1$)$ has been investigated. The V2F model is also employed to analyze the air-exchange rate $(\mathrm{ACH})$ for a series of two-dimensional building arrangements, such as step-up and step-down configurations, having different aspect ratios and relative heights of the buildings, a design quite underexplored in the literature.

This paper is organized as follows: firstly, the experimental setup used in the water channel and the numerical approach followed in the simulation are described. Secondly, tests of the V2F model through comparisons with the experimental data and results obtained employing other turbulence models are presented and discussed together with the analyses of several flow regimes referred to several ARs and $H_{2} / H_{1}$. Particular attention is also paid to the analysis of canyon ventilation as well as to its dependence on the canyon geometry. This paper concludes with a summary of the main results.

\section{The Water-Channel Experiments}

The numerical simulations have been validated with a series of experiments conducted in the close-loop water channel located at the Laboratory of Hydraulics of the 


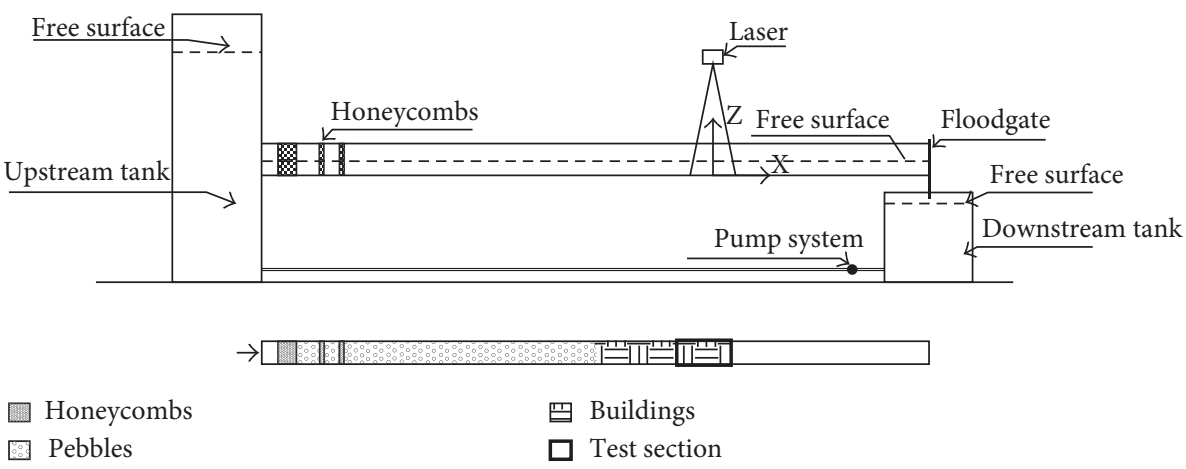

Figure 1: Side and top views of the experimental apparatus. The $x$-axis refers to the longitudinal axis of the channel (streamwise), while the $z$-axis is parallel to the vertical.

University of Rome "La Sapienza." The water channel allows the reproduction of the atmospheric boundary layer with several advantages [38-41]. One of them is that image analysis techniques, such as particle tracking velocimetry, can be easily employed. These permit accurate spatial measurements, which generally allow a clearer understanding of complex flows such as the one under investigation.

The water channel has a rectangular cross section of $0.35 \mathrm{~m}$ height and $0.25 \mathrm{~m}$ width and $7.4 \mathrm{~m}$ length (Figure 1). The flow rate is set by a floodgate placed at the closing section of the channel, and the water depth, $h=0.16 \mathrm{~m}$, is maintained constant throughout the experiments (more information about the facility can be found in [42]). The reference frame has been defined with the $x$-axis aligned with the streamwise velocity and the $z$-axis vertical. The water is seeded with nonbuoyant particles ( $2 \mu \mathrm{m}$ in diameter), which were assumed to be passively transported by the flow. Upwind of the buildings, the channel bottom is covered by unevenly spaced, roughness elements (pebbles with an average diameter of $5 \mathrm{~mm}$ ) in order to reproduce the logarithmic vertical profile of the undisturbed streamwise velocity as well as the (nearly) constant Reynolds stress profile typically observed in the atmospheric boundary layer.

The roughness Reynolds number, $\operatorname{Re}_{\tau}=u_{*} H / v$ (here, $u_{*}=$ $\sqrt{-\overline{u^{\prime} w^{\prime}}}$ is the friction velocity, $v=10^{-6} \cdot \mathrm{m}^{2} \cdot \mathrm{s}^{-1}$ is the kinematic viscosity of water, and $H$ is the obstacle height), ranges from 340 up to 470; that is, it is well above the critical value of 70 given by Snyder [43], which guarantees the independence of the investigated large-scale structures and the mean flow of Reynolds number effects [44]. Therefore, in our experiments, $\mathrm{Re}_{\tau}$ is large enough to ensure both the conditions of full turbulence of the simulated boundary layer and the dynamic similarity between experiments and real conditions.

The urban canopy is composed of a $2 \mathrm{D}$ regular array of urban-like obstacles with square sections of $B=H=20 \mathrm{~mm}$ and length $25 \mathrm{~cm}$ glued onto the channel bottom (Figure 2). Two geometrical configurations have been investigated, one referred to the skimming flow $(\mathrm{AR}=1)$ and one to the wakeinterference regime $(A R=0.5)$. To this end, the distance between the obstacles, $W$, has been varied from $20 \mathrm{~mm}$ to $40 \mathrm{~mm}$.

The framed area is $99 \mathrm{~mm}$ long ( $x$-axis) and $72 \mathrm{~mm}$ high ( $z$-axis) and is located in correspondence with the 20th canyon, where the flow can be considered fully developed. The velocity components along the $x$ - and $z$-axes, respectively, $u$ and $w$, have been measured using the feature tracking (FT), a technique based on the image analysis [45]. A high-speed camera (CMOS with a resolution of $1280 \times 1024$ pixels) acquires images at 250 frames per second for $40 \mathrm{~s}$ during each experiment, while a green laser light sheet (wavelength of $532 \mathrm{~nm}$ ) illuminates the acquisition area. Velocities have been determined by the FT algorithm from the displacements of the seeding particles between successive frames. A Gaussian interpolation algorithm [46] was applied to the scattered velocity samples to obtain a twodimensional, Eulerian description of the motion on the $x-z$ plane. After this procedure, 10000 instantaneous flow fields (each $1 / 250 \mathrm{~s}$ ) with a spatial resolution of $1 \mathrm{~mm}$ have been obtained. Details of the undisturbed approaching flow are given in [47].

\section{The Numerical Approach}

3.1. Mathematical Formulation. In the case of incompressible, turbulent flows, Ansys Fluent solves the balance equations of mass and momentum and additional transport equations related to closure assumptions. In particular, the first two equations can be expressed as follows (Einstein summation rule applies):

$$
\begin{gathered}
\frac{\partial \bar{u}_{i}}{\partial x_{i}} \\
\bar{u}_{j} \frac{\partial \bar{u}_{i}}{\partial x_{j}}=-\frac{1}{\rho} \frac{\partial \bar{p}}{\partial x_{i}}+\frac{\mu}{\rho} \frac{\partial^{2} \bar{u}_{i}}{\partial x_{j}^{2}}-\frac{\partial}{\partial x_{j}}\left(\overline{u_{i}^{\prime} u_{j}^{\prime}}\right)+g_{i},
\end{gathered}
$$

where $g_{i}$ is the acceleration due to gravity, $p$ the pressure, $\mu$ the viscosity, and $\rho$ the density. The Reynolds stress tensor $u_{i}^{\prime} u_{j}^{\prime}$ (here, prime indicates fluctuation around the mean) is usually modeled using a linear proportionality to the rate of strain (Boussinesq eddy-viscosity model): 


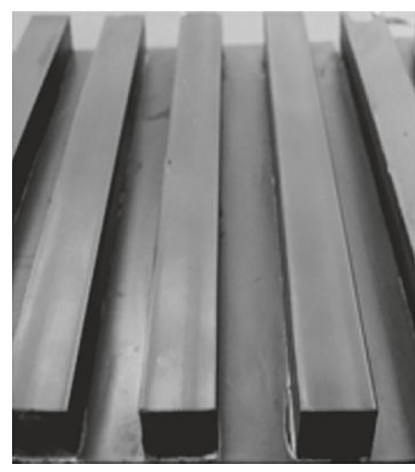

(a)

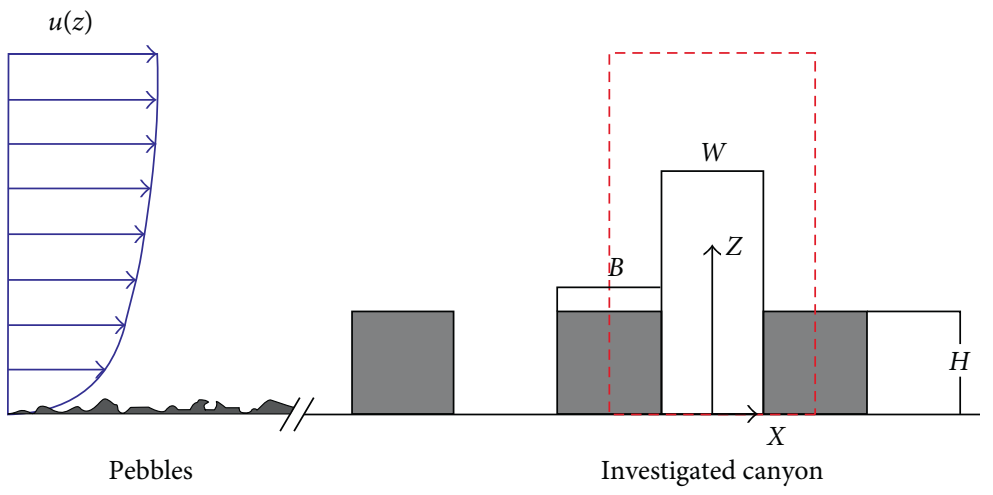

(b)

Figure 2: Obstacles set for $A R=1$ (a). Sketch of the vertical section (b).

$$
-\overline{u_{i}^{\prime} u_{j}^{\prime}}=\frac{\mu_{t}}{\rho}\left(\frac{\partial \bar{u}_{i}}{\partial x_{j}}+\frac{\partial \bar{u}_{j}}{\partial x_{i}}\right)-\frac{2}{3} \delta_{i j} k
$$

where $\delta_{i j}$ is the Kronecker delta. The turbulent kinetic energy $k$ and the eddy viscosity $\mu_{t}$ are determined by adding to (1) and (2) two or more additional equations [48]. Since the three $k-\varepsilon$ models, the two $k-\omega$ models and the RSM, implemented in Ansys Fluent are well known and widely employed in the literature, only the V2F model is briefly described below.

3.2. The V2F Model. Standard eddy-viscosity models use specific damping functions to simulate the region close to the solid boundary. This is because the $k-\varepsilon$ closure for $\mu_{t}$ is isotropic, while near-wall turbulence is strongly anisotropic [49]. The V2F model was developed to avoid the use of damping functions and correctly reproduce the attenuation of the turbulence near solid boundaries [25, 31]. This model solves an elliptic relaxation function, $f$, and three transport equations, respectively, for $k, \varepsilon$, and $\overline{v^{2}}$, where the latter is the velocity scale. The V2F model is based on a turbulent viscosity hypothesis proposed by Durbin for the region close to the solid boundary [49]:

$$
\mu_{t}=\rho C_{\mu} \overline{v^{2}} T
$$

where $T=k / \varepsilon$ and $C_{\mu}$ is a constant. Information on the anisotropy of the flow in the near-wall region is taken through the transport equation of $\overline{v^{2}}$, which, in turn, is derived from the transport equation of the Reynolds stress normal to the wall. Summarizing, the transport equations for $k, \mathcal{\varepsilon}$, and $\overline{v^{2}}$ are, respectively, read as follows:

$$
\begin{aligned}
\frac{\partial}{\partial t}(\rho k)+\frac{\partial}{\partial x_{i}}\left(\rho k \bar{u}_{i}\right)= & P-\rho \varepsilon+\frac{\partial}{\partial x_{j}}\left[\left(\mu+\frac{\mu_{t}}{\sigma_{k}}\right) \frac{\partial k}{\partial x_{j}}\right]+S_{k} \\
\frac{\partial}{\partial t}(\rho \varepsilon)+\frac{\partial}{\partial x_{i}}\left(\rho \varepsilon \bar{u}_{i}\right)= & \frac{C_{\varepsilon 1}{ }^{\prime} P-C_{\varepsilon 2}{ }^{\prime} \rho \varepsilon}{T} \\
& +\frac{\partial}{\partial x_{j}}\left[\left(\mu+\frac{\mu_{t}}{\sigma_{\varepsilon}}\right) \frac{\partial \varepsilon}{\partial x_{j}}\right]+S_{\varepsilon}
\end{aligned}
$$

$$
\begin{aligned}
\frac{\partial}{\partial t}\left(\rho \overline{v^{2}}\right)+\frac{\partial}{\partial x_{i}}\left(\rho \bar{v}^{2} \bar{u}_{i}\right)= & \rho k f-6 \rho \overline{v^{2}} \frac{\varepsilon}{k} \\
& +\frac{\partial}{\partial x_{j}}\left[\left(\mu+\frac{\mu_{t}}{\sigma_{\overline{v^{2}}}}\right) \frac{\partial \overline{v^{2}}}{\partial x_{j}}\right]+S_{\overline{v^{2}}}
\end{aligned}
$$

where $S_{k}, S_{\varepsilon}$, and $S_{\overline{v^{2}}}$ are source terms, while

$$
\begin{aligned}
P & =2 \mu_{\mathrm{t}} S^{2}, \\
S^{2} & =S_{i j} S_{i j}, \\
S_{i j} & =\frac{1}{2}\left(\frac{\partial \bar{u}_{i}}{\partial x_{j}}+\frac{\partial \bar{u}_{j}}{\partial x_{i}}\right) .
\end{aligned}
$$

The function $f$, included to take into account the anisotropic wall effects, is modeled by solving an elliptic Helmholtz-type equation:

$$
f-L^{2} \frac{\partial^{2} f}{\partial x_{j}^{2}}=\left(C_{1}-1\right) \frac{(2 / 3)\left(\overline{v^{2}} / k\right)}{T}+C_{2} \frac{P}{\rho k} \frac{5\left(\overline{v^{2}} / k\right)}{T}+S_{f},
$$

where $L$ is a length scale, $C_{1}$ and $C_{2}$ are constants, and $S_{\mathrm{f}}$ is a source term. More information on the V2F model can be found in [48].

3.3. Geometry and Numerical Domain. The building array described in Section 2 has been numerically modeled by considering a $3 \mathrm{D}$ domain (Figure 3 ). It is composed of twelve buildings and, consequently, eleven street canyons. According to [50], the computational domain has been extended in the streamwise direction to $10 \mathrm{H}$ between the inflow boundary and the first building and to $20 \mathrm{H}$ between the last building and the outflow boundary. Its height has been set equal to $10 H$. The numerical runs have also been conducted considering a $2 \mathrm{D}$ computational domain corresponding to the vertical section passing through the channel axis (Figure 4 and the grey plane in Figure 3). This procedure has been followed since the investigated domain is symmetric along the $y$-axis. The choice of a 2D model allows lower computational costs without compromising the accuracy of the results [14-18]. 


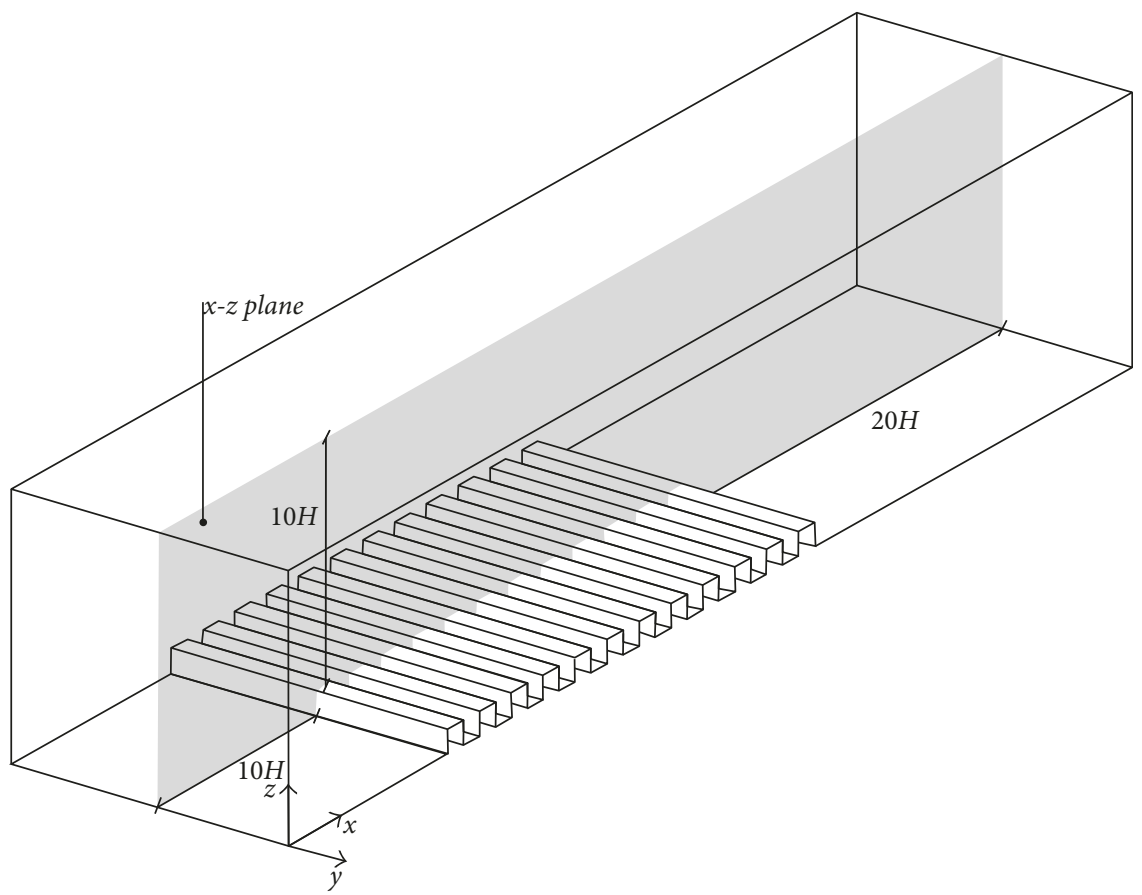

Figure 3: The computational domain for the 3D simulation. $H$ indicates the building height.

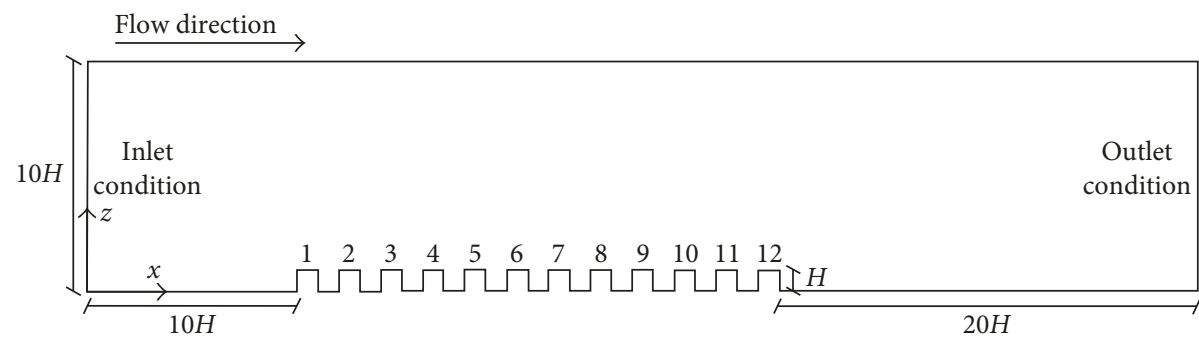

FIgURE 4: The computational domain for the $2 \mathrm{D}$ case.

In order to test the effectiveness of this choice, both the $3 \mathrm{D}$ and $2 \mathrm{D}$ models have been run and compared with the experimental data. The results of this test will be shown below. In addition to the cases $\mathrm{AR}=0.5$ and 1 with buildings of equal height used to test the model capability, other geometries have been taken into account. In particular, five arrays of buildings with different ARs $(0.5,1,1.33,2$, and 4$)$ have also been investigated varying $H_{2} / H_{1}(0.4,0.5,0.7,1.5$, 2, and 2.5) for each of the five ARs.

3.4. Boundary Conditions and Simulation Settings. The vertical profile of the magnitude of the undisturbed mean velocity, $V$, measured in the water channel upwind of the building array (interpolated by using a fitting function implemented in Ansys Fluent) has been set as the velocity inlet boundary condition at the inflow. Here, $V$ assumes the meaning of time average of the 10000 instantaneous velocity magnitudes collected during the experiment. The flow has been considered not affected by any obstacle at its boundary since the inlet velocity profile is fully developed. For this reason, a free-slip condition has been applied to the bottom surface before and after the building array. A zero (relative) pressure has been imposed as the outlet boundary condition. It is used to force the flow in the direction normal to the outlet without any backflow. A free-slip condition has been imposed at the water-air boundary, while a no-slip condition has been applied at the surfaces of the buildings and at the bottom of the canyon as well. This choice is justified on the basis of several tests we conducted, which showed a better agreement between measured and simulated flows inside the canyon.

The numerical solver has employed a structured, nonorthogonal, fully collocated, cell-centered, finite-volume approach for the discretization of the computational domain, and the velocity vector has been decomposed into its Cartesian components. Physical diffusive cell fluxes have been approximated using a conventional second-order central differencing scheme, and the SIMPLE algorithm [51] has been used for pressure correction. The convergence target based on the root mean square has been set to $10^{-7}$. The quantities of interest, such as velocity and turbulent kinetic energy, have been monitored at several grid 


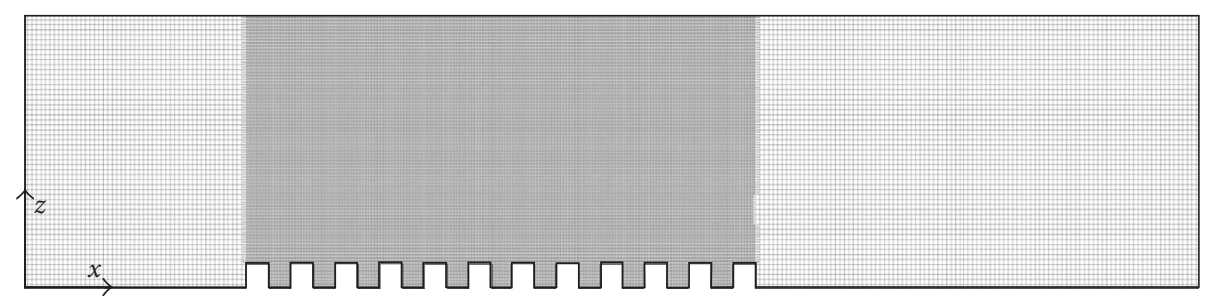

Figure 5: Mesh used for $\mathrm{AR}=1$.

points during the solving process to check whether stable levels before convergence were met or not.

3.5. Mesh and Grid Independence Test. Both the 3D and 2D domains have been discretized by using orthogonal grids (Figure 5). Since the geometry is relatively simple, a blockbased hexahedral mesh has been used to enhance the quality of the mesh. The grid lines have been refined near the solid surfaces (bottom, rooftops, and building walls).

The choice of the most suitable mesh spacing is not a trivial task since the use of a too coarse mesh can give rise to considerable errors, while an excessively fine mesh costs in terms of computing time. This is the reason why any CFD simulation should be preceded by a series of grid independence tests. The velocity magnitude $V$ computed at $z / H=7.5$ in correspondence with the vertical profiles passing through the center of the ninth canyon (the reason for this choice is clarified in the next section) has been analyzed as a function of four grid meshes of different densities (Table 1). Assuming Mesh A (interval size equal to $0.001 \mathrm{~m}$ ) as the pivot case, the percentage difference $\Delta(\%)$ between Mesh A and the finest of the four (Mesh D) is only $0.08 \%$. Therefore, in the remainder of this work, Mesh A is used for all the CFD analyses. The same interval size of the mesh has been employed for the 3D model, for a total amount of nearly 1.2 million cells.

The vertical profiles of the nondimensional velocity, $V / \bar{u}_{\text {ref }}$, passing through the center of the ninth canyon are given in Figure 6 for the case $A R=1$. The results show an overall good agreement between the experiment and simulations. The percentage difference between the $2 \mathrm{D}$ and $3 \mathrm{D}$ cases is nearly $5.30 \%$ for the entire profile. Therefore, it is possible to assume that the $2 \mathrm{D}$ model describes the flow field with the same accuracy as the $3 \mathrm{D}$ model.

3.6. Stabilization Analysis. Since the interrogation area adopted during the experiments is located far enough from the inlet to assure the flow independence along the streamwise direction, before starting the comparisons, it is essential to verify whether the same condition holds for the CFD simulations or not. This test has been conducted for $\mathrm{AR}=1$ by analyzing the $V / \bar{u}_{\text {ref }}$ vertical profiles passing through the center of each of the 11 canyons. The percentage differences between the velocity magnitudes calculated for two contiguous canyons have been evaluated within the canyon $(0<z / H \leq 1)$ and in the boundary layer above $(z / H>1)$ (Table 2). Such differences become small from the fourth building onward, after which a well-defined trend towards the equilibrium occurs. This trend stabilizes after
TABle 1: Characteristics of the four meshes used for the grid independence test and corresponding percentage differences $\Delta$.

\begin{tabular}{lcccc}
\hline & Mesh A & Mesh B & Mesh C & Mesh D \\
\hline $\begin{array}{l}\text { Number of cells } \\
\text { Mesh interval size }\end{array}$ & 104896 & 32350 & 14275 & 394576 \\
$\begin{array}{l}\text { within the canyon (m) } \\
\text { Velocity magnitude }\end{array}$ & 0.001 & 0.002 & 0.004 & 0.0005 \\
$\left(\mathrm{~ms}^{-1}\right)$ & 0.225996 & 0.225531 & 0.225273 & 0.225800 \\
$\Delta(\%)$ & 0.08 & 0.20 & 0.32 & - \\
\hline
\end{tabular}

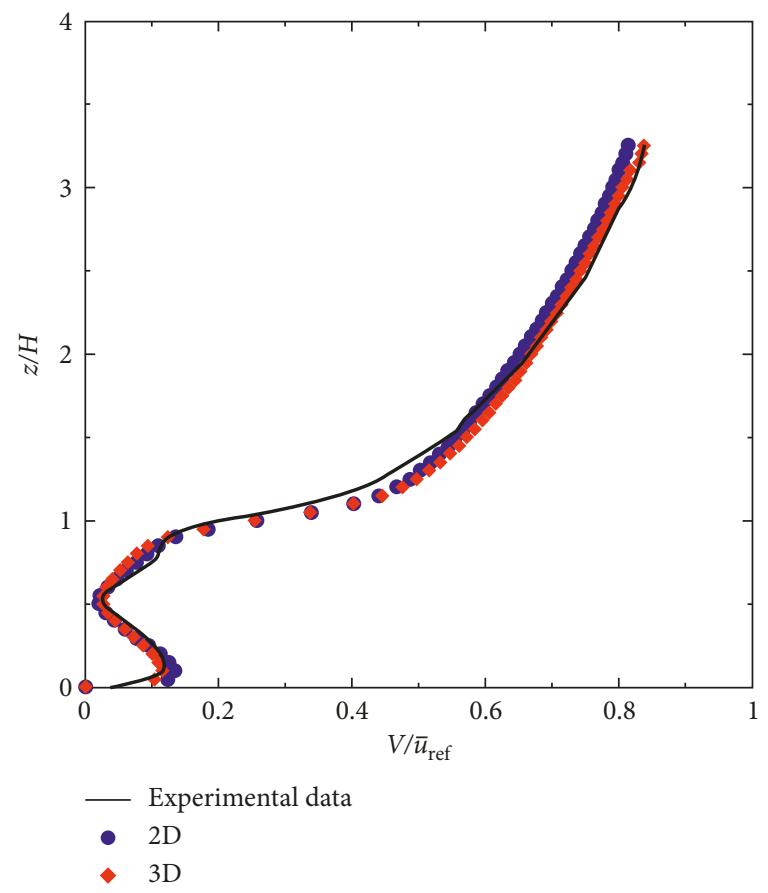

FIGURE 6: Vertical profiles, passing through the center of the ninth canyon, of the nondimensional velocity magnitude calculated using the $2 \mathrm{D}$ (blue circles) and the $3 \mathrm{D}$ (red diamonds) models for $\mathrm{AR}=1$. The continuous line refers to the experimental data. The height is normalized by the building height, $H$.

the ninth canyon, where $\Delta$ is almost constant $(\approx 0.35 \%)$. For this reason, from now on, it is implicit that the vertical profile considered for comparisons is the one passing through the center of the ninth canyon.

3.7. Turbulence Model Evaluation. In this section, the average velocities calculated by means of numerical simulations conducted using seven turbulence models implemented in Ansys 
TABLE 2: Percentage differences between the velocity magnitudes calculated along the vertical profiles passing through the center of two contiguous canyons.

\begin{tabular}{lccccccccccc}
\hline & Canyon & 1 & 2 & 3 & 4 & 5 & 6 & 7 & 8 & 9 \\
\hline $0<z / H \leq 1$ & $\Delta(\%)$ & 34.20 & 11.63 & 3.47 & 1.61 & 0.90 & 0.67 & 0.57 & 0.35 & 0.34 & 0.33 \\
$z / H>1$ & $\Delta(\%)$ & 4.54 & 2.07 & 1.13 & 0.73 & 0.51 & 0.37 & 0.27 & 0.25 & 0.23 & 0.21 \\
\hline
\end{tabular}

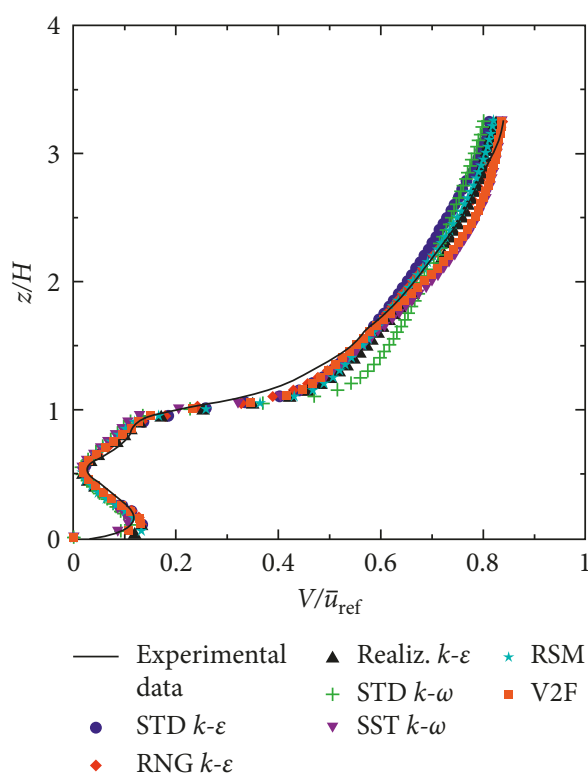

(a)

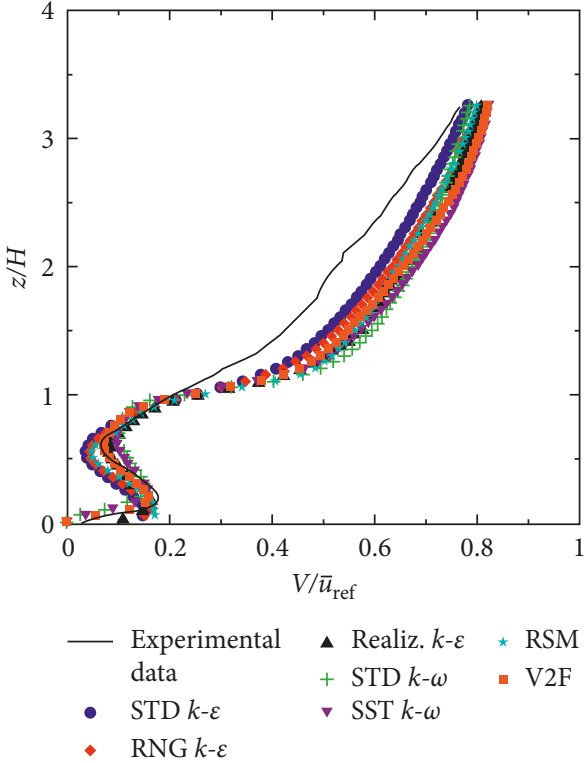

(b)

FIGURE 7: Comparison between simulated (symbols) and measured (line) vertical profiles of $V / \bar{u}_{\text {ref }}$ passing through the center of the canyon for $\mathrm{AR}=1$ (a) and $\mathrm{AR}=0.5$ (b).

Fluent are compared with those measured in the water channel. The turbulence models employed in the analysis are the standard (STD) $k-\varepsilon$ model [52], renormalization group (RNG) $k-\varepsilon$ model [53], realizable $k-\varepsilon$ model [54], standard (STD) $k-\omega$ model [55], shear stress transport (SST) $k-\omega$ model [56], Reynolds stress model (RSM) [57], and $\overline{v^{2}}-f$ (V2F) model [24]. The aim is to assess the accuracy of the V2F model in estimating the velocity profiles and the flow field within the canyon for both the skimming flow $(\mathrm{AR}=1)$ and the wakeinterference regime $(\mathrm{AR}=0.5)$.

Figure 7 shows the comparisons between the observed (line) and simulated (symbols) vertical profiles of $V / \bar{u}_{\text {ref }}$ for $\mathrm{AR}=1$ (Figure 7(a)) and 0.5 (Figure 7(b)). Overall, the velocity above the canyon is lower for $\mathrm{AR}=0.5$, that is, for the wake-interference regime, in agreement with the field campaign measurements [54]. The simulated profiles do not differ considerably, and the differences with the measured profiles are reasonably small, even though a general underestimation occurs within the canyon. In contrast, the model generally overestimates the velocity above the canyons. However, the $\mathrm{V} 2 \mathrm{~F}$ model gives velocity profiles closer to those observed in both the analyzed flow regimes (see the percentage differences listed in Tables 3 and 4 among the seven turbulence models obtained for the two ARs).

The V2F model results have been compared with the experimental data also to assess its capability to capture global flow characteristics such as the number and location of the
TABle 3: Percentage differences between measured and modeled velocities within and above the canyon $(A R=1)$.

\begin{tabular}{lccccccc}
\hline & $\begin{array}{c}\text { STD } \\
k-\varepsilon\end{array}$ & $\begin{array}{c}\text { RNG } \\
k-\varepsilon\end{array}$ & $\begin{array}{c}\text { Real } \\
k-\varepsilon\end{array}$ & $\begin{array}{c}\text { STD } \\
k-\omega\end{array}$ & $\begin{array}{c}\text { SST } \\
k-\omega\end{array}$ & RSM & V2F \\
\hline $\begin{array}{l}z / H>0, \\
\Delta(\%)\end{array}$ & 8.88 & 7.05 & 8.55 & 13.42 & 11.25 & 10.60 & 8.01 \\
$\begin{array}{l}0<z / H \leq 1, \\
\begin{array}{l}(\%) \\
z / H>1,\end{array}\end{array}$ & 18.82 & 17.47 & 17.78 & 23.16 & 24.30 & 24.40 & 15.72 \\
$\Delta(\%)$ & 4.46 & 2.42 & 4.44 & 9.09 & 5.45 & 4.46 & 4.59 \\
\hline
\end{tabular}

TABle 4: Percentage differences between measured and modeled velocities within and above the canyon $(A R=0.5)$.

\begin{tabular}{lccccccc}
\hline & $\begin{array}{c}\text { STD } \\
k-\varepsilon\end{array}$ & $\begin{array}{c}\text { RNG } \\
k-\varepsilon\end{array}$ & $\begin{array}{c}\text { Real } \\
k-\varepsilon\end{array}$ & $\begin{array}{c}\text { STD } \\
k-\omega\end{array}$ & $\begin{array}{c}\text { SST } \\
k-\omega\end{array}$ & RSM & V2F \\
\hline $\begin{array}{l}z / H>0, \\
\begin{array}{l}(\%) \\
0<z / H \leq 1,\end{array}\end{array}$ & 19.53 & 20.70 & 19.30 & 25.72 & 24.38 & 22.66 & 19.30 \\
$\begin{array}{l}\Delta(\%) \\
z / H>1,\end{array}$ & 31.89 & 26.21 & 12.14 & 26.15 & 20.71 & 22.72 & 10.56 \\
$\Delta(\%)$ & 14.04 & 18.26 & 22.48 & 25.53 & 26.01 & 22.63 & 23.19 \\
\hline
\end{tabular}

vortex structures formed within the canyon. The correct simulation of the vortex topology is of great importance [58], for example, for the determination of the concentration of 


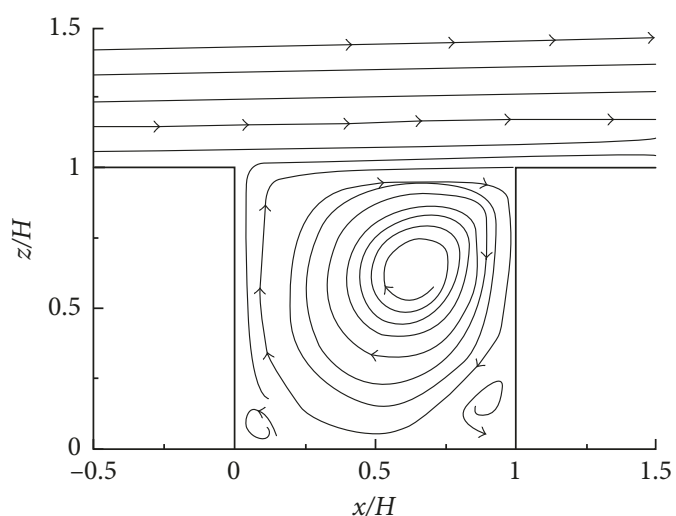

(a)

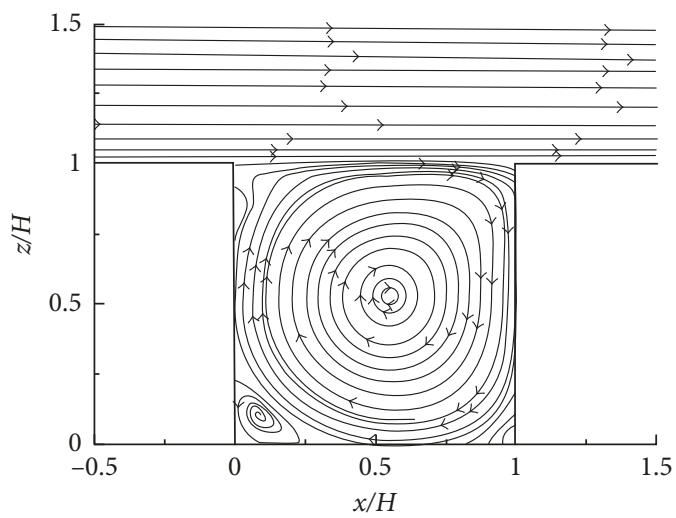

(c)

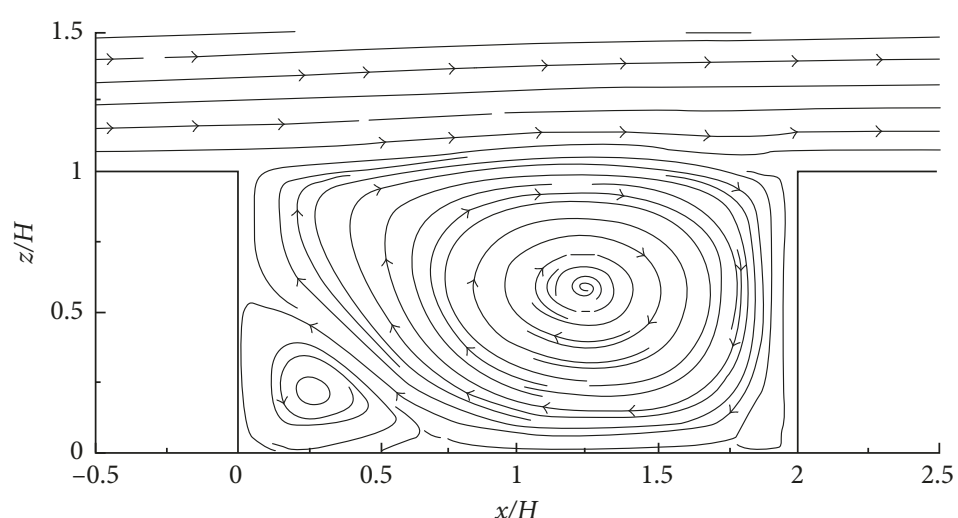

(b)

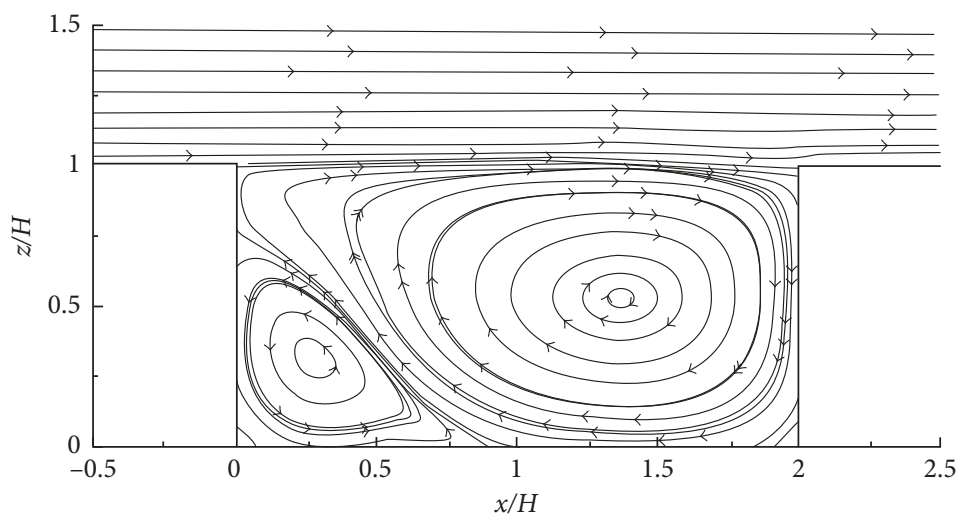

(d)

FiguRE 8: Streamlines of the mean velocity magnitude for $A R=1$ measured in the laboratory (a) and simulated (c) and for $A R=0.5$ measured in the laboratory (b) and simulated (d).

pollutants emitted within the canyon $[59,60]$, particularly when the source is located at the street level.

The three $k-\varepsilon$ models results also show a good agreement with the experiments, especially for $\mathrm{AR}=1$, while the two $k$ $\omega$ models and the RSM, in particular, always show the larger differences. This is understandable in that the Reynolds number within the canyon is not large and the $k-\varepsilon$ models are more accurate in these conditions [55]. In contrast, the V2F models are recognized as giving better performance for both low-Reynolds number and wall-bounded flows. Overall, it is possible to conclude that the $\mathrm{V} 2 \mathrm{~F}$ model reproduces the velocity profiles inside the canyon better than the other turbulence models.

Figure 8 shows the maps for the two ARs of the streamlines associated with the measured (Figures 8(a) and $8(\mathrm{~b}))$ and simulated (Figures $8(\mathrm{c})$ and $8(\mathrm{~d})$ ) velocities. All of them conform to the canonical configuration of the canopy flow, that is, a current nearly parallel to the streamwise direction above the canopy and a main vortex within the canyon, characterized by lower velocity. For $A R=1$, the CFD simulates also a counterclockwise recirculating region located in the upper part of the facet of the leeward building and other two smaller vortices, located at the bottom corners. These data also match other results reported in the literature [60-64]. Both measurements and simulations show that the size of the secondary vortex located at the bottom of the leeward building grows with $\mathrm{AR}$. At $\mathrm{AR}=0.5$, indeed, it shows two adjacent vortices: the downstream one is by far the larger and rotates clockwise, while the upstream one is smaller, occupying nearly $1 / 4$ of the canyon and rotates counterclockwise. This pattern is in agreement with experimental data and numerical simulations performed in [9, 60, 61, 63-65].

In conclusion, among the seven turbulence models considered here, the model V2F shows the best agreement with the experimental data, particularly within the canyon. Furthermore, it requires the shortest calculation time.

3.8. Effects of Aspect Ratio and Building Height Variations on the Canyon Ventilation. Once the V2F model performance has been verified against experimental data, the same model has been used to investigate urban street canyons characterized by variants of the skimming flow for narrow canyons $(A R>1)$ and for variations of the relative height of the buildings $H_{2} / H_{1} \neq 1$. The goal is to quantify the air ventilation properties of the canyon making use of the airexchange rate $(\mathrm{ACH})$. The latter is a measure of the rate of air removal from the street canyon [66]:

$$
\mathrm{ACH}=\int_{W} w_{+} d x
$$




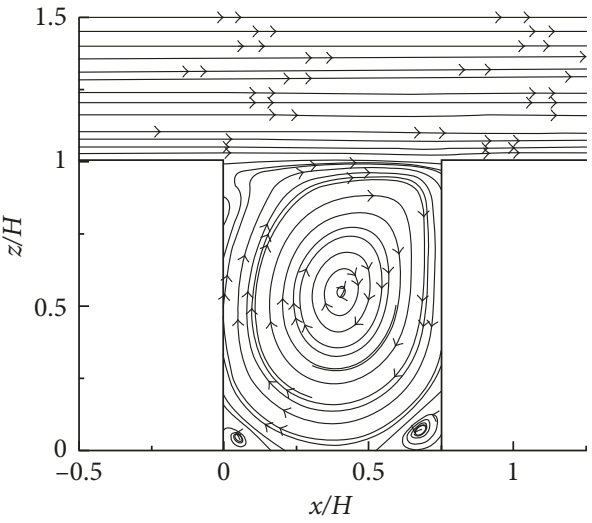

(a)

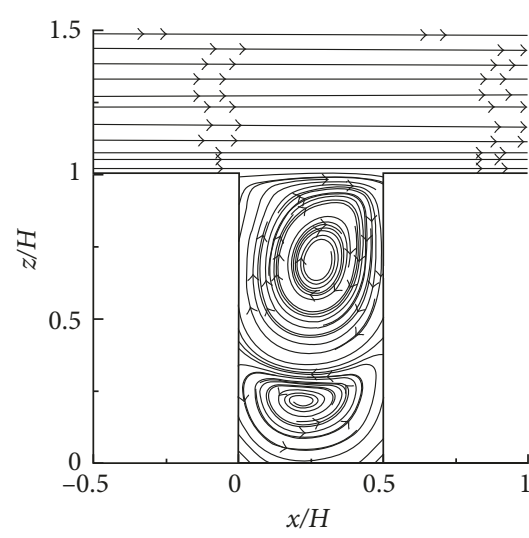

(b)

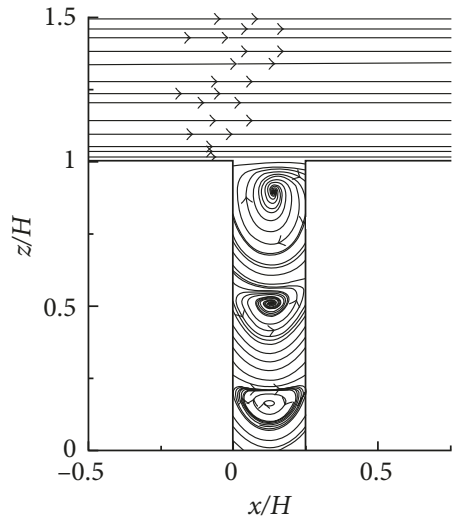

(c)

Figure 9: Streamlines of the simulated velocity magnitude for $\mathrm{AR}=1.33$ (a), $\mathrm{AR}=2$ (b), and $\mathrm{AR}=4$ (c).

where the subscript "+" indicates positive (upward) vertical velocity, while $W$ is the canyon length. Since RANS models do not calculate the instantaneous velocity components, according to [67], ACH has been estimated as the sum of its average and fluctuating parts:

$$
\mathrm{ACH}=\int_{W} \bar{w}_{+} d x+\int_{W} w^{\prime} d x=\overline{\mathrm{ACH}}+\mathrm{ACH}^{\prime},
$$

where the contribution $w^{\prime}$ is obtained from $\mu_{t}$ and $k$ by using (3) and assuming isotropic conditions. The computational parameters and settings adopted in the previous section have also been employed for these additional analyses.

3.9. Effect of Aspect Ratio Variations. Street canyons with $\mathrm{AR}>1.54$ are characterized by the multivortex flow regime. Compared to $\mathrm{AR}=1$, this variant of the skimming flow involves a higher reduction of the wind speed within the canyon and lower vertical diffusion of pollutants emitted within the cavity [9]. Three narrower street canyons with $\mathrm{AR}>1(\mathrm{AR}=1.33, \mathrm{AR}=2$, and $\mathrm{AR}=4)$ have therefore been investigated to analyze their ventilation properties.

The multivortex configurations in the skimming flow have firstly been analyzed in terms of streamlines (Figure 9). The results show the transition from the one-vortex regime to the multivortex regime as $\mathrm{AR}$ increases. The case $\mathrm{AR}=1.33$ (Figure 9(a)) still shows the main clockwise vortex as seen for $\mathrm{AR}=1$ (Figure 8(c)), but the two recirculation zones at the canyon bottom are more noticeable. For $\mathrm{AR}=2$, these two vortices merge to form a larger counterclockwise structure (Figure 9(b)). The canyon is therefore divided into two regions, one lying above the other, where the upper recirculation is stronger and drives the lower vortex. The upper recirculation is still shifted downstream $(x=0.26 \mathrm{H}$, $z=0.71 H$ ), according to $\mathrm{AR}=1$, while the lower, flatter vortex is centered in the cavity $(x=0.26 H, z=0.22 H)$. These results agree reasonably well with the water-channel experiments performed by Baik et al. [68] for $\mathrm{AR}=2$, which showed $(x=0.32 \mathrm{H}, z=0.75 H)$ and $(x=0.29 H, z=0.17 H)$ as the locations of the centers of the upper and lower recirculation regions, respectively.
Further increases in AR lead to the formation of additional vortices within the cavity. For example, for $\mathrm{AR}=4$, three vertically aligned vortices are formed (Figure 9(c)), with increasing dimensions upwards. The configuration of narrow buildings is particularly interesting for the investigation of dispersion phenomena. In fact, pollutants typically emitted by vehicular traffic at the canyon bottom through linear sources are trapped in the lower part of the canyon, where strong values of mean and standard deviation of concentration occur near the sidewalks [7, 69], directly affecting the final receptor. Furthermore, the external wind flows above the canopy almost parallel to the roofs, resulting in a poor canyon ventilation process, are strongly hampered by the structure of the vortices. This corroborates the idea that, for the skimming flow, the fluid has difficulty in penetrating the interelement spaces, and therefore it skims, remaining nearly parallel to the roofs $[68,70]$. For this reason, it is fundamental to consider a correct urban planning to minimize unwanted effects of pollutant accumulation.

By comparing the vertical profile of $V / \bar{u}_{\text {ref }}$ calculated for all the ARs (Figure 10), it can be seen that, above the canyon, it depends appreciably on AR. On the contrary, $V / \bar{u}_{\text {ref }}$ changes considerably with AR within the canyon, especially going from the standard skimming flow to the multivortex regime. While the velocity magnitude for $\mathrm{AR}=1.33$ is similar to that seen for $\mathrm{AR}=1$, it drastically drops for $\mathrm{AR}=2$ and 4 , indicating that the multivortex flow is characterized by very poor ventilation, particularly at the street level. The results presented above conform to those presented in $[9,58,61,65-67,71]$, which simulated canopy flows through CFD, employing different turbulence models.

The nondimensional air ventilation components for the five ARs are shown in Figure 13 (see data points referring to $\left.H_{2} / H_{1}=1\right)$. While the mean contribution $\overline{\mathrm{ACH}} /\left(\bar{u}_{\mathrm{ref}} W\right)$ does not change appreciably with $\mathrm{AR}$, the lower the aspect ratio, the higher the $\mathrm{ACH}^{\prime} /\left(\bar{u}_{\text {ref }} W\right)$. This suggests that turbulence plays a major role in air exchanges between the canyon and the overlying layer. This is particularly true for the wake-interference regime, where 


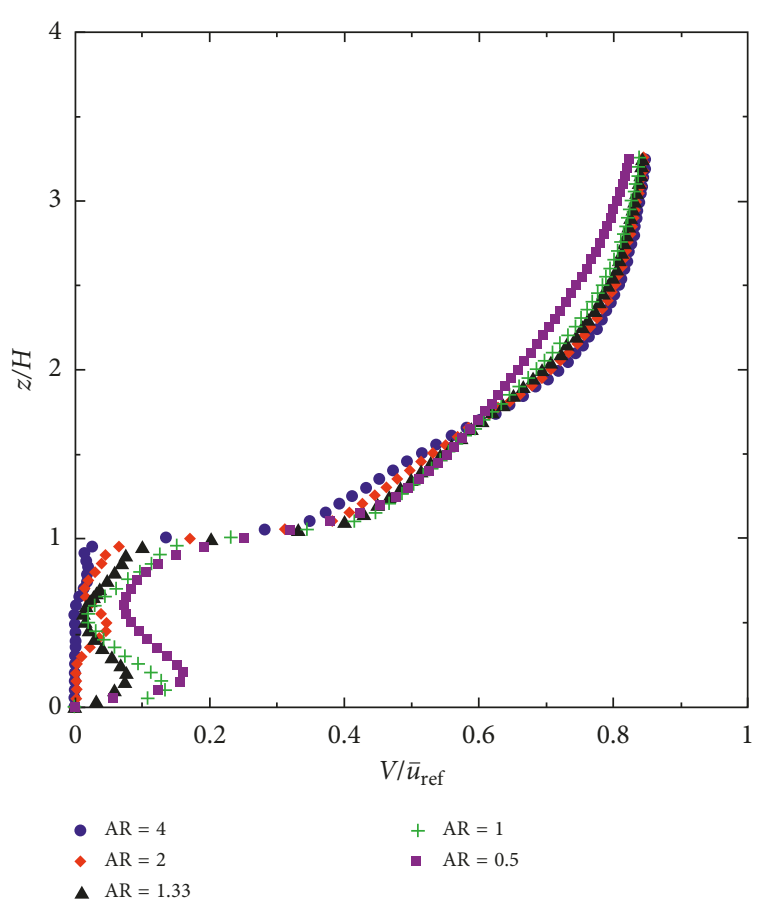

Figure 10: Comparison among the simulated vertical profiles of $V / \bar{u}_{\text {ref }}$ passing through the center of the canyon for $\mathrm{AR}=4, \mathrm{AR}=2$, $\mathrm{AR}=1.33, \mathrm{AR}=1$, and $\mathrm{AR}=0.5$.

$\overline{\mathrm{ACH}}$ is nearly an order of magnitude greater than $\mathrm{ACH}^{\prime}$. However, a question here arises regarding the significance of the air-exchange rate for the multivortex flow. In fact, since $\mathrm{ACH}$ depends only on the flow kinematics around the upper part of the canyon, it cannot provide any information on the actual air exchange occurring at the cavity bottom, where the second (or third) vortex is located. Therefore, the use of ACH for evaluating the ventilation performance of a street canyon and its relation with pollutant removal mechanisms must be considered with circumspection for multivortex regimes.

3.10. Effect of Building Height Variations. Another geometrical factor that considerably influences the ventilation in the urban street canyon is the relative height of the buildings, $\mathrm{H}_{2} / \mathrm{H}_{1}$. This parameter has already been investigated in other works $[62,72-77]$ for $2 \mathrm{D}$ flows, while useful insights into the effects of building height variations for arrays of $3 \mathrm{D}$ buildings have recently been reported in [78-80]. The additional analysis we provide here focuses on the combined effect of the variability of both building heights and AR. Six $H_{2} / H_{1}$ have been considered for each of the five ARs, in particular the step-up configurations, where the leeward building $\left(H_{1}\right)$ is shorter than the windward building $\left(H_{2} / H_{1}=1.5,2\right.$, and 2.5$)$, and the step-down configurations, where the leeward building is taller than the windward building $\left(H_{2} / H_{1}=0.4,0.5\right.$, and 0.7$)$.

Figure 11 shows the streamlines obtained for the stepup geometry $\left(H_{2} / H_{1}>1\right)$. For $\mathrm{AR}=0.5$ and $H_{2} / H_{1}=1.5$ (Figure 11(a)), the flow field does not depart significantly from that observed for $H_{2} / H_{1}=1$ (Figure 9(a)), in agreement with the numerical results in [64]. The size of the main vortex increases as $H_{2} / H_{1}$ increases (Figures $11(\mathrm{f})$ and $11(\mathrm{k})$ ), and its center does not move appreciably along the $x$-axis, while it moves upward, reaching about the height of the leeward building. At the bottom of the canyon, the recirculation zone at the corner of the leeward building becomes smaller as $H_{2} / H_{1}$ increases, while the anticlockwise vortex at the corner with the windward building progressively increases in size. A similar behavior occurs for $\mathrm{AR}=1$ (Figures 11(b), 11(g), and 11(l)).

Regarding the other skimming flows, their dependence on $H_{2} / H_{1}$ is somehow greater. The progressive ejection of the upper vortex from the canyon into the overlying layer observed for $\mathrm{AR}=1.33$ (Figures 11(c), 11(h), and 11 $(\mathrm{m})$ ), in fact, is increasingly evident going from $\mathrm{AR}=2$ (Figures 11(d), 11(i), and 11(n)) to 4 (Figures 11(e), 11(j), and 11(o)). While for $\mathrm{AR}=2$ and $H_{2} / H_{1}=1.5$, the center of the upper vortex is located at $z \approx H_{1}$ (Figure 11(d)) and it progressively moves upward as $H_{2} / H_{1}$ grows, and for $H_{2} / H_{1}=2.5$, the vortex is practically outside of the canyon. Similar considerations can be drawn for the case $\mathrm{AR}=1.33$, which shows the transition from the standard skimming flow when $H_{2} / H_{1}=1$ (Figure 9(a)) to the multivortex regime for $H_{2} / H_{1}>1$ (Figures 11(c), 11(h), and 11(m)). The recirculation zones at the bottom of the canyon are combined together, and two counterrotating vortices occupy the canyon.

In terms of air ventilation, $\mathrm{ACH}^{\prime} /\left(\bar{u}_{\text {ref }} W\right)$ always exceeds its average counterpart, $\overline{\mathrm{ACH}} /\left(\bar{u}_{\text {ref }} W\right)$, even though not to a large extent as for $H_{2} / H_{1}=1$. Furthermore, $\mathrm{ACH}$ does not depend significantly on $H_{2} / H_{1}$ when $A R=1$ and 2, while a clear decrease in $\mathrm{ACH}$ for increasing $\mathrm{H}_{2} / \mathrm{H}_{1}$ takes place for the other aspect ratios. In particular, taller windward buildings allow lower vertical mass transfer between the canyon and the overlying region.

Finally, Figure 12 shows the flow patterns for the stepdown configurations $\left(H_{2} / H_{1}<1\right)$. They are characterized by a wide clockwise vortex placed over the canyon and the top of the windward building. Overall, the lower the $H_{2} / H_{1}$, the smaller the $\mathrm{ACH}$ (Figure 13(c)), with the exception of the case $\left(\mathrm{AR}=2, \mathrm{H}_{2} / H_{1}=0.67\right)$, when there is only a large vertical structure occupying both the canyon and the overlying region up to $z \approx H_{1}$ (Figure $12(\mathrm{a})$ ). The latter configuration corresponds with the largest $\mathrm{ACH}$ calculated in the present analysis and is mainly associated with large $\overline{\mathrm{ACH}}$. In contrast, for all the other step-down configurations investigated here, the main vortex (or the two or more vortices, when $A R \geq 1.33$ ) remains confined within the canyon. The latter represents the main difference between step-up and step-down configurations, and it might have great influence on the concentration of pollutants emitted within the canyon, particularly at the street level.

Lastly, we note that, from the point of view of air quality analysis, the development of secondary vortices in the lower corners of the canyon for $\mathrm{AR}=0.5$ and 1 should determine an accumulation of pollutants near the sidewalks in the case of vehicular traffic emissions, whatever be the value of the height ratio. For $\mathrm{AR}=1.33$ and 2, the presence of the two 


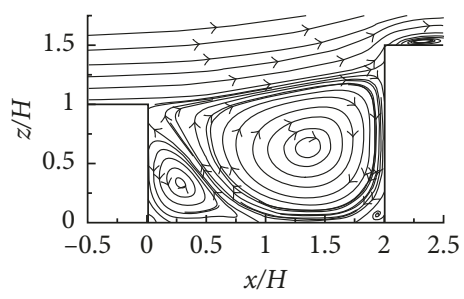

(a)

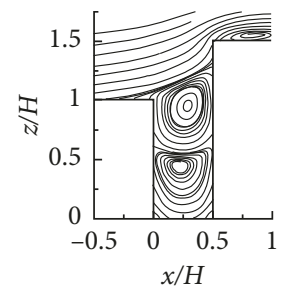

(d)

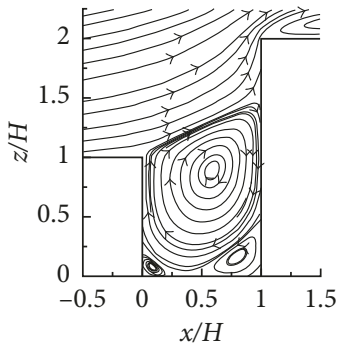

(g)

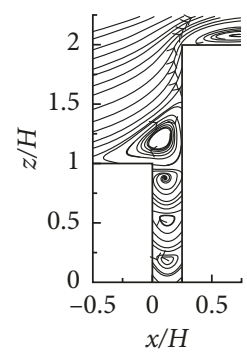

(j)

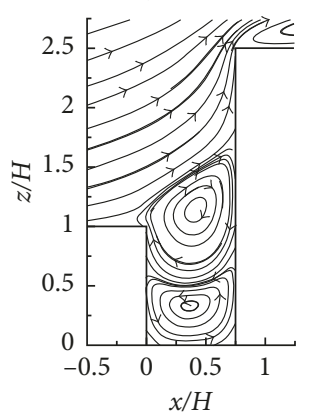

(m)

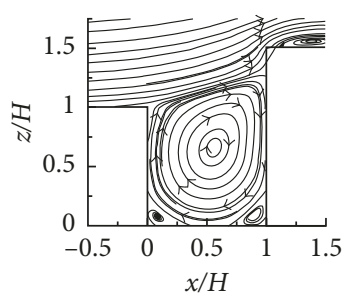

(b)

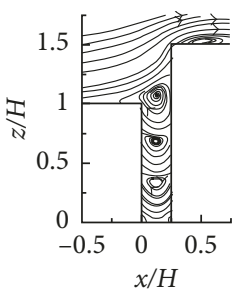

(e)

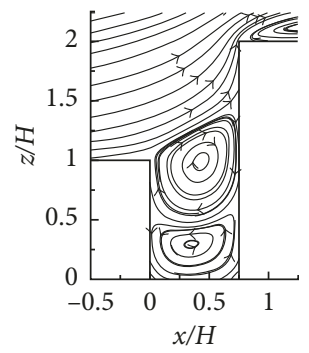

(h)

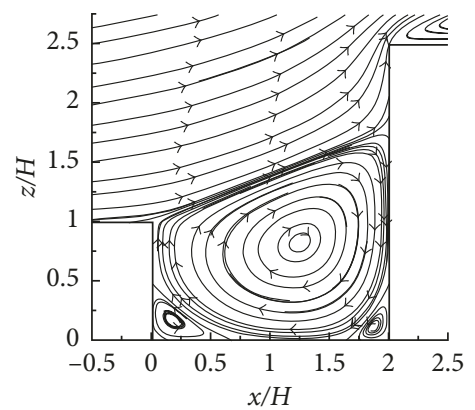

(k)

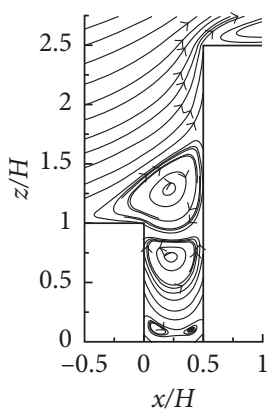

(n)

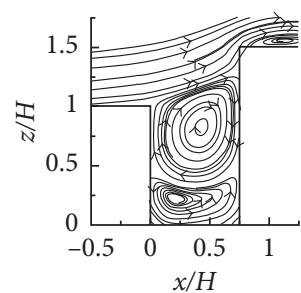

(c)

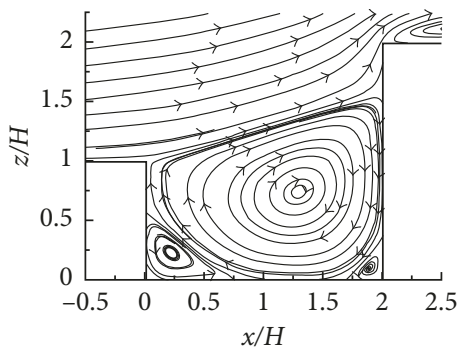

(f)

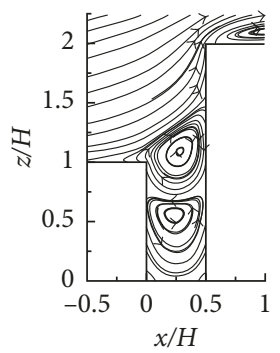

(i)

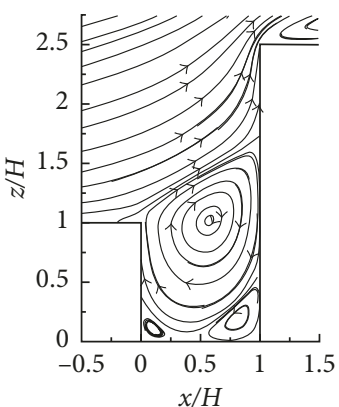

(l)

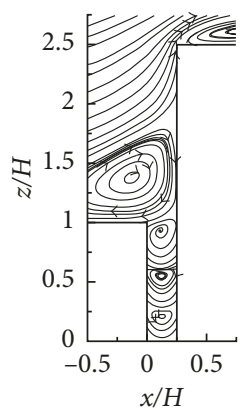

(o)

FIgURE 11: Streamlines of the simulated velocity magnitude $V$ for AR $=0.5$ with $H_{2} / H_{1}=1.5$ (a), $H_{2} / H_{1}=2$ (f), and $H_{2} / H_{1}=2.5$ (k); for $\mathrm{AR}=1$ with $H_{2} / H_{1}=1.5$ (b), $H_{2} / H_{1}=2(\mathrm{~g})$, and $H_{2} / H_{1}=2.5$ (l); for $\mathrm{AR}=1.33$ with $H_{2} / H_{1}=1.5$ (c), $H_{2} / H_{1}=2$ (h), and $H_{2} / H_{1}=2.5$ (m); for $\mathrm{AR}=2$ with $H_{2} / H_{1}=1.5$ (d), $H_{2} / H_{1}=2(\mathrm{i})$, and $H_{2} / H_{1}=2.5(\mathrm{n})$; for $\mathrm{AR}=4$ with $H_{2} / H_{1}=1.5(\mathrm{e}), H_{2} / H_{1}=2(\mathrm{j})$, and $H_{2} / H_{1}=2.5$ (o). 


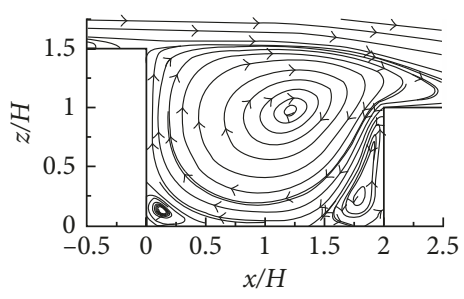

(a)

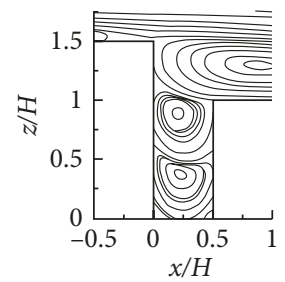

(d)

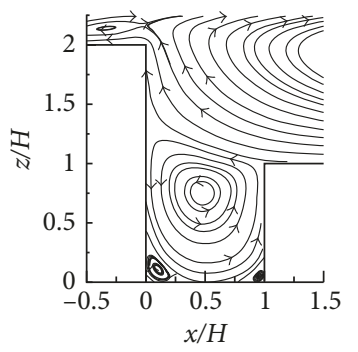

(g)

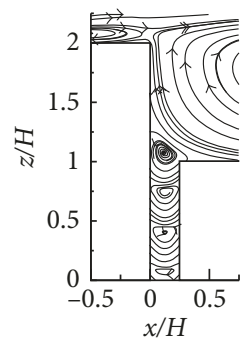

(j)

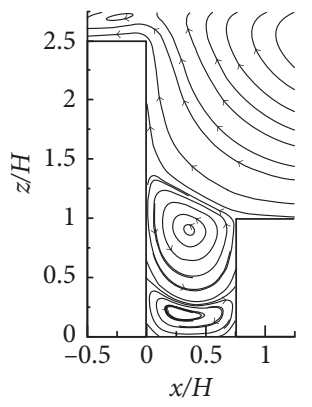

(m)

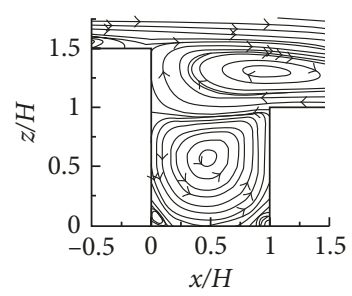

(b)

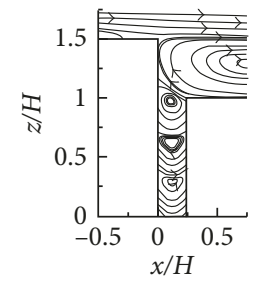

(e)

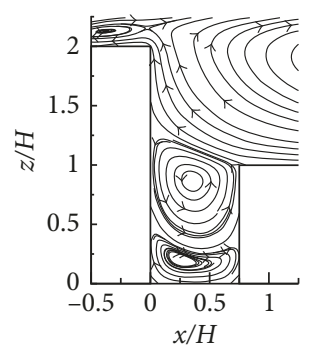

(h)

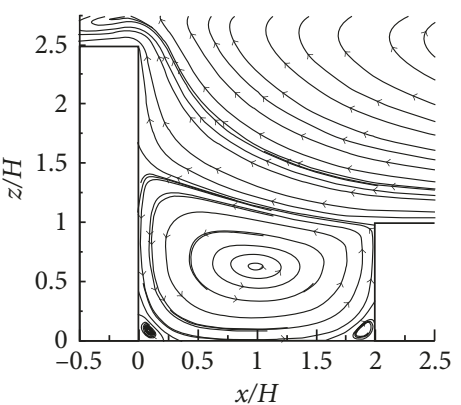

(k)

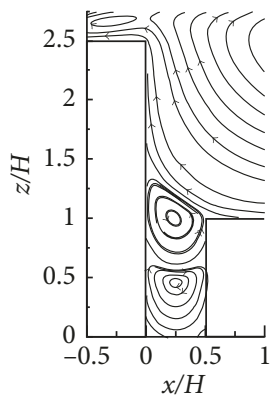

(n)

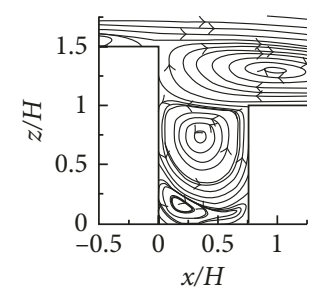

(c)

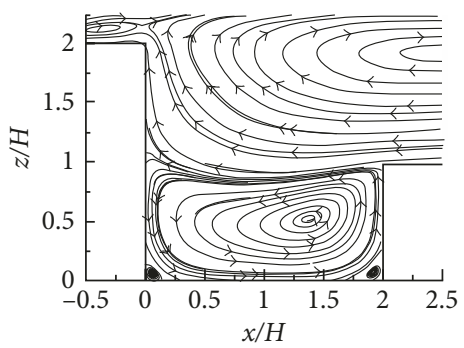

(f)

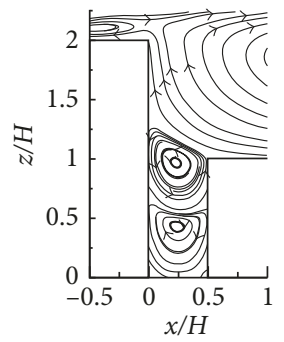

(i)

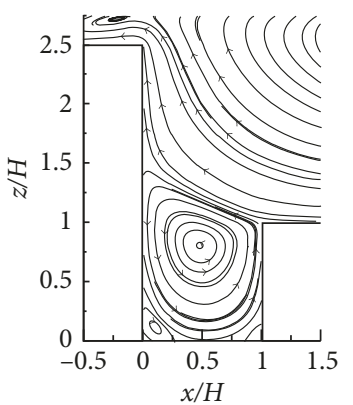

(1)

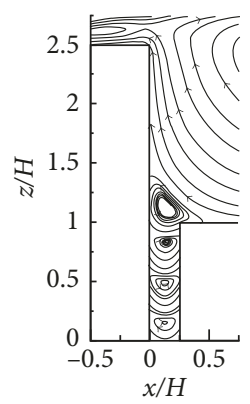

(o)

FIGURE 12: Streamlines of the simulated velocity magnitude $V$ for $\mathrm{AR}=0.5$ with $H_{2} / H_{1}=0.67$ (a), $H_{2} / H_{1}=0.5$ (f), and $H_{2} / H_{1}=0.4$ (k); for $\mathrm{AR}=1$ with $H_{2} / H_{1}=0.67(\mathrm{~b}), H_{2} / H_{1}=0.5(\mathrm{~g})$, and $H_{2} / H_{1}=0.4(\mathrm{l})$; for $\mathrm{AR}=1.33$ with $H_{2} / H_{1}=0.67(\mathrm{c}), H_{2} / H_{1}=0.5(\mathrm{~h})$, and $H_{2} / H_{1}=0.4(\mathrm{~m})$; for $\mathrm{AR}=2$ with $H_{2} / H_{1}=0.67(\mathrm{~d}), H_{2} / H_{1}=0.5(\mathrm{i})$, and $H_{2} / H_{1}=0.4(\mathrm{n})$; for $\mathrm{AR}=4$ with $H_{2} / H_{1}=0.67(\mathrm{e}), H_{2} / H_{1}=0.5(\mathrm{j})$, and $H_{2} / H_{1}=0.4(\mathrm{o})$. 


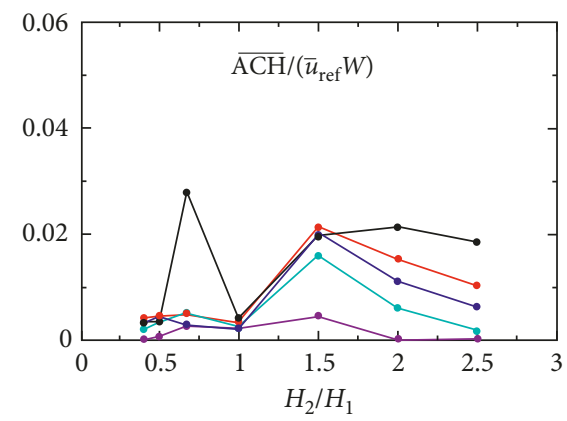

AR

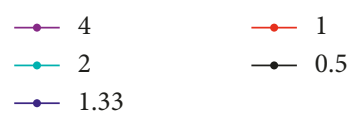

(a)
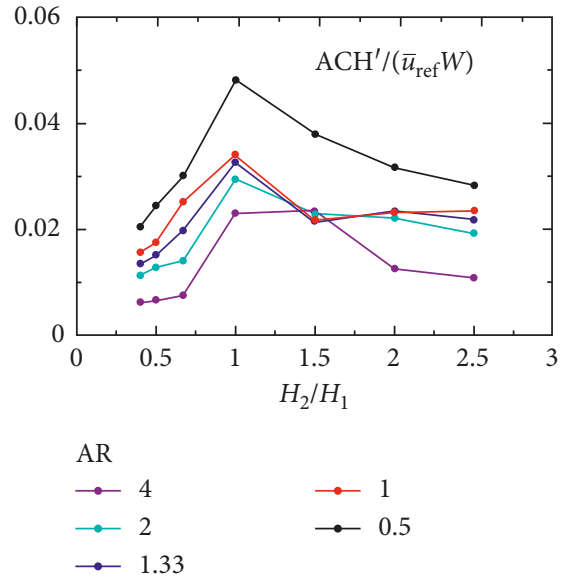

(b)
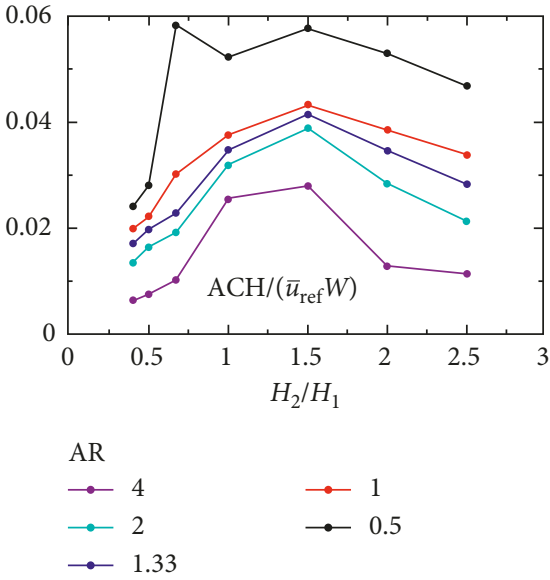

(c)

Figure 13: Nondimensional ACH components as a function of the relative building heights for five aspect ratios: (a) mean component, (b) turbulent component, and (c) total $\mathrm{ACH}$.

counterrotating vortices further limits the ventilation in the canyon, especially in the portion closest to the ground. For $\mathrm{AR}=4$, the vertically aligned multiple vortices configuration strongly inhibits the exchange of air with the higher levels and paves the way to the stagnation of pollutants at the pedestrian level.

\section{Summary and Conclusions}

Water-channel data have been used to diagnose the capability of the $\overline{v^{2}}-f(\mathrm{~V} 2 \mathrm{~F})$ turbulence model, implemented in Ansys Fluent, to reproduce the flow field in a regular array of $2 \mathrm{D}$ buildings. The experiments refer to two very common geometrical configurations, that is, the skimming flow $(\mathrm{AR}=1)$ and the wake-interference regime $(\mathrm{AR}=0.5)$. One of the strengths of the V2F model is the equation of the turbulent viscosity, which takes into account the anisotropy of the flow in the near-wall region through the modeling of a velocity scale. The performances of the V2F model have been compared with those of other six turbulence models implemented in Ansys Fluent. The results have shown that the V2F model gives the best results with shorter computational time.

Further simulations conducted using the V2F model have made it possible to analyze canyon ventilation for a variety of aspect ratios and step-up and step-down configurations by calculating the air-exchange rate $(\mathrm{ACH})$. For the step-up configurations $\left(H_{2} / H_{1}>1\right)$, the increase of the relative height of the buildings does not appreciably change the total $\mathrm{ACH}$ for both the wake-interference and the skimming flows, while a certain decrease of ACH occurs for $\mathrm{AR}>1.33$. On the contrary, step-down configurations $\left(H_{2} / H_{1}<1\right)$ appear to be in general less ventilated and therefore more prone to pollutant recirculation. For all the geometries investigated, the air ventilation is mainly determined by turbulent motions with the exception of the wake-interference regime for $H_{2} / H_{1}=0.67$, the latter canyon geometry being characterized by the largest contribution of the mean $\mathrm{ACH}$.
In conclusion, the V2F turbulence model has proved to be a useful tool for wind engineers as well as for investigations concerning air quality control and urban planning.

\section{Conflicts of Interest}

The authors declare that there are no conflicts of interest regarding the publication of this paper.

\section{Acknowledgments}

This research was partially supported by the BRiC (ID 22) fund from INAIL (Project VIEPI: "Integrated evaluation of particulate pollutant for indoor air quality") and the RG11715C7D43B2B6 fund from the University of Rome " $\mathrm{La}$ Sapienza".

\section{References}

[1] C. W. Kent, S. Grimmond, J. Barlow et al., "Evaluation of urban local-scale aerodynamic parameters: implications for the vertical profile of wind speed and for source areas," Boundary-Layer Meteorology, vol. 164, no. 2, pp. 183-213, 2017.

[2] A. Pelliccioni, P. Monti, and G. Leuzzi, "Wind-speed profile and roughness sublayer depth modelling in urban boundary layers," Boundary-Layer Meteorology, vol. 160, no. 2, pp. 225-248, 2016.

[3] T. R. Oke, "Street design and urban canopy layer climate," Energy and Buildings, vol. 11, no. 1-3, pp. 103-113, 1988.

[4] F. Nardecchia, F. Gugliermetti, and F. Bisegna, "A novel approach to CFD analysis of the urban environment," Journal of Physics: Conference Series, vol. 655, article 012013, 2015.

[5] A. Salvati, H. Coch Roura, and C. Cecere, "Assessing the urban heat island and its energy impact on residential buildings in Mediterranean climate: Barcelona case study," Energy and Buildings, vol. 146, pp. 38-54, 2017.

[6] B. Blocken, T. Stathopoulos, J. Carmeliet, and L. M. Hensen, "Application of computational fluid dynamics in building performance simulation for the outdoor environment: an 
overview," Journal of Building Performance Simulation, vol. 4, no. 2, pp. 157-184, 2011.

[7] A. Di Bernardino, P. Monti, G. Leuzzi, and G. Querzoli, "Pollutant fluxes in two-dimensional street canyons," Urban Climate, vol. 24, pp. 80-93, 2018.

[8] S. Ferrari, M. G. Badas, M. Garau, A. Seoni, and G. Querzoli, "The air quality in narrow two-dimensional urban canyons with pitched and flat roof buildings," International Journal of Environment and Pollution, vol. 62, no. 2-4, pp. 347-368, 2017.

[9] J. F. Sini, S. Anquetin, and P. G. Mestayer, "Pollutant dispersion and thermal effects in urban street canyon," Atmospheric Environment, vol. 30, no. 15, pp. 2659-2677, 1996.

[10] Y.-K. Ho and C.-H. Liu, "Street-level ventilation in hypothetical urban areas," Atmosphere, vol. 8, no. 12, p. 124, 2017.

[11] M. Immer, J. Allegrini, and J. Carmeliet, "Time-resolved and time-averaged stereo-PIV measurements of a unit-ratio cavity," Experiments in Fluids, vol. 57, no. 6, pp. 57-101, 2016.

[12] J. J. O'Neill, X.-M. Cai, and R. Kinnersley, "Stochastic backscatter modelling for the prediction of pollutant removal from an urban street canyon: a large-eddy simulation," Atmospheric Environment, vol. 142, pp. 9-18, 2016.

[13] M. Garau, M. G. Badas, S. Ferrari, A. Seoni, and G. Querzoli, "Turbulence and air exchange in a two-dimensional urban street canyon between gable roof buildings," Boundary-Layer Meteorology, vol. 167, no. 1, pp. 123-143, 2018.

[14] Y. Huang, X. Hu, and N. Zeng, "Impact of wedge-shaped roofs on airflow and pollutant dispersion inside urban street canyons," Building and Environment, vol. 44, no. 12, pp. 23352347, 2009.

[15] R. A. Memon, D. Y. C. Leung, and C. H. Liu, "Effects of building aspect ratio and wind speed on air temperatures in urban-like street canyons," Building and Environment, vol. 45, no. 1, pp. 176-188, 2010.

[16] F. Murena and B. Mele, "Effect of short-time variations of wind velocity on mass transfer rate between street canyons and the atmospheric boundary layer," Atmospheric Pollution Research, vol. 5, no. 3, pp. 484-490, 2014.

[17] J. Allegrini, V. Dorer, and J. Carmeliet, "Buoyant flows in street canyons: validation of CFD simulations with wind tunnel measurements," Building and Environment, vol. 72, no. 63, pp. 63-74, 2014.

[18] Y.-K. Ho, C.-H. Liu, and M. S. Wong, "Preliminary study of the parameterisation of street-level ventilation in idealised two-dimensional simulations," Building and Environment, vol. 89, pp. 345-355, 2015.

[19] G. Xie, S. Zheng, W. Zhang, and B. Sundén, "A numerical study of flow structure and heat transfer in a square channel with ribs combined downstream half-size or same-size ribs," Applied Thermal Engineering, vol. 61, no. 2, pp. 289-300, 2013.

[20] X. M. Cai, J. F. Barlow, and S. E. Belche, "Dispersion and transfer of passive scalars in and above street canyons-largeeddy simulations," Atmospheric Environment, vol. 42, no. 23, pp. 5885-5895, 2008.

[21] D. Hamlyn and R. A. Britter, "Numerical study of the flow field and exchange processes within a canopy of urban-type roughness," Atmospheric Environment, vol. 39, no. 18, pp. 3243-3254, 2005.

[22] R. Ramponi and B. Blocken, A Computational Study on the Influence of Urban Morphology on Wind-Induced Outdoor Ventilation, International Environmental Modelling and Software Society (iEMSs), Manno, Switzerland, 2012.

[23] ANSYS Inc., ANSYS Fluent Software Package, v. 14.5, User's Guide, ANSYS Inc., Canonsburg, PA, USA, 2009.
[24] P. A. Durbin, "Separated flow computations with the k-epsilonv-squared model," AIAA Journal, vol. 33, no. 4, pp. 659-664, 1995.

[25] D. R. Laurence, J. C. Uribe, and S. V. Utyuzhnikov, "A robust formulation of the $v^{2}-f$ model," Flow, Turbulence and Combustion, vol. 73, no. 3-4, pp. 169-185, 2004.

[26] S. Parneix and P. A. Durbin, Numerical Simulation of $3 D$ Turbulent Boundary Layers Using the $v^{2}-f$ Model, Annual Research Briefs Center For Turbulence Research, NASA/ Stanford University, Stanford, CA, USA, 1997.

[27] R. Rossi and G. Iaccarino, "Numerical analysis and modeling of plume meandering in passive scalar dispersion downstream of a wall-mounted cube," International Journal of Heat and Fluid Flow, vol. 43, pp. 137-148, 2013.

[28] M. Behnia, S. Parneix, and P. A. Durbin, "Prediction of heat transfer in a jet impinging on a flat plate," International Journal of Heat and Mass Transfer, vol. 41, no. 12, pp. 1845-1855, 1998.

[29] A. B. Bhagwat and A. Sridharan, "Convective heat transfer from a heated plate to the orthogonally impinging air jet," Journal of Thermal Science and Engineering Applications, vol. 8, no. 4, article 041009, 2016.

[30] A. K. Pujari, B. V. S. S. S. Prasad, and N. Sitaram, "Effect of blowing ratio on the internal heat transfer of a cooled nozzle guide vane in a linear cascade," Journal of Thermal Science and Engineering Applications, vol. 8, no. 4, article 041004, 2016.

[31] R. Manceau, S. Parneix, and D. Laurence, "Turbulent heat transfer predictions using the $v^{2}-f$ model on unstructured meshes," International Journal of Heat and Fluid Flow, vol. 21, no. 3, pp. 320-328, 2000.

[32] L. Marrocco and A. Franco, "Direct numerical simulation and RANS comparison of turbulent convective heat transfer in staggered ribbed channel with high blockage," Journal of Heat Transfer, vol. 139, no. 2, article 021701, 2017.

[33] G. Kalitzin, Application of the $v^{2}-f$ Model to Aerospace Configurations, Center for Turbulence Research Ann Res Briefs, Stanford, CA, USA, 1999.

[34] F.-S. Lien and G. Kalitzin, "Computations of transonic flow with the $v^{2}-f$ turbulence model," International Journal of Heat and Fluid Flow, vol. 22, no. 1, pp. 53-61, 2001.

[35] Z. Zhang, W. Zhang, Z. Zhai, and Q. Chen, "Evaluation of various turbulence models in predicting airflow and turbulence in enclosed environments by CFD: part-2: comparison with experimental data from literature," HVAC\&R Research, vol. 13, no. 6, pp. 871-886, 2007.

[36] C. Heschl, Y. Tao, K. Inthavong, and J. Tu, "Improving predictions of heat transfer in indoor environments with eddy viscosity turbulence models," Building Simulation, vol. 9, no. 2, pp. 213-220, 2016.

[37] Z. Zhang and Q. Chen, "Prediction of particle deposition onto indoor surfaces by CFD with a modified Lagrangian method," Atmospheric Environment, vol. 43, no. 2, pp. 319-328, 2009.

[38] J.-J. Baik, R. E. Park, H. Y. Chun, and J.-J. Kim, "A laboratory model of urban street-canyon flows," Journal of Applied Meteorology, vol. 39, no. 9, pp. 1592-1600, 2000.

[39] H. Liu, B. Liang, F. Zhu, B. Zhang, and J. Sang, "A laboratory model for the flow in urban street canyons induced by bottom heating," Advances in Atmospheric Sciences, vol. 20, no. 4, pp. 554-564, 2003.

[40] P. Huq and P. Franzese, "Measurements of turbulence and dispersion in three idealized urban canopies with different aspect ratios and comparison with a Gaussian plume model," Boundary-Layer Meteorology, vol. 147, no. 1, pp. 103-121, 2013. 
[41] X.-X. Li, D. Y. C. Leung, and C.-H Liu, "Physical modeling of flow field inside urban street canyons," Journal of Applied Meteorology and Climatology, vol. 47, no. 7, pp. 2058-2067, 2007.

[42] A. Di Bernardino, P. Monti, G. Leuzzi, and G. Querzoli, "Water-channel study of flow and turbulence past a twodimensional array of obstacles," Boundary-Layer Meteorology, vol. 155, no. 1, pp. 73-85, 2015.

[43] W. H. Snyder, "Guideline for fluid modeling of atmospheric diffusion," EPA Tech. Rep. EPA-600/8-81-009, Environmental Protection Agency, Washington, DC, USA, 1981.

[44] K. Uehara, S. Wakamatsu, and R. Ooka, "Studies on critical Reynolds number indices for wind-tunnel experiments on flow within urban areas," Boundary-Layer Meteorology, vol. 107, no. 2, pp. 353-370, 2003.

[45] A. Cenedese, Z. Del Prete, M. Miozzi, and G. Querzoli, “A laboratory investigation of the flow in the left ventricle of a human heart with prosthetic, tilting-disk valves," Experiments in Fluids, vol. 39, no. 2, pp. 322-335, 2005.

[46] P. Monti, G. Querzoli, A. Cenedese, and S. Piccinini, "Mixing properties of a stably stratified parallel shear layer," Physics of Fluids, vol. 19, no. 8, article 085104, 2007.

[47] A. Di Bernardino, P. Monti, G. Leuzzi, and G. Querzoli, "Water-channel estimation of Eulerian and Lagrangian time scales of the turbulence in idealized two-dimensional urban canopies," Boundary-Layer Meteorology, vol. 165, no. 2, pp. 251-276, 2017.

[48] ANSYS Inc., ANSYS Fluent Software Package, v. 14.5, Theory Guide, ANSYS Inc., Canonsburg, PA, USA, 2013.

[49] P. A. Durbin, "Near-wall turbulence closure modeling without "damping functions"," Theoretical and Computational Fluid Dynamics, vol. 3, pp. 1-13, 1991.

[50] J. Franke, A. Hellsten, H. Schlùnzen, and B. Carissimo, Best Practice Guideline for the CFD Simulation of Flows in the Urban Environment, COST Action 732, Meteorological Inst., Norway, 2007.

[51] S. V. Patankar, Numerical Heat Transfer and Fluid Flow, Hemisphere Publishing Corporation, New York, NY, USA, 1980.

[52] B. E. Launder and D. B. Spalding, Lectures in Mathematical Models of Turbulence, Academic Press, London, UK, 1972.

[53] D. Choudhury, Introduction to the Renormalization Group Method and Turbulence Modeling, Fluent Inc., New York, NY, USA, Technical Memorandum TM-107, 1983.

[54] T.-H. Shih, W. W. Liou, A. Shabbir, Z. Yang, and J. Zhu, “A new $k-\varepsilon$ eddy-viscosity model for high Reynolds number turbulent flows: model development and validation," Computer and Fluids, vol. 24, no. 3, pp. 227-238, 1995.

[55] D. C. Wilcox, Turbulence Modeling for CFD, DCW Industries, Inc., La Cañada Flintridge, CA, USA, 1998.

[56] F. R. Menter, "Two-equation eddy-viscosity turbulence models for engineering applications," AIAA Journal, vol. 32, no. 8, pp. 1598-1605, 1994.

[57] M. M. Gibson and B. E. Launder, "Ground effects on pressure fluctuations in the atmospheric boundary layer," Journal of Fluid Mechanics, vol. 86, no. 3, pp. 491-511, 1978.

[58] F. Nardecchia, F. Gugliermetti, and F. Bisegna, "How temperature affects the airflow around a single-block isolated building," Energy and Buildings, vol. 118, pp. 142-151, 2016.

[59] A. Amicarelli, P. Salizzoni, G. Leuzzi et al., "Sensitivity analysis of a concentration fluctuation model to dissipation rate estimates," International Journal of Environment and Pollution, vol. 48, no. 1-4, pp. 164-173, 2012.
[60] J.-J. Baik and J.-J. Kim, "A numerical study of flow and pollutant dispersion characteristics in urban street canyons," Journal of Applied Meteorology, vol. 38, no. 11, pp. 1576-1589, 1999.

[61] A. Kovar-Panskus, P. Louka, J. F. Sini et al., "Influence of geometry on the mean flow within urban street canyons-a comparison of wind tunnel experiments and numerical simulations," Water, Air, and Soil Pollution, vol. 2, no. 5-6, pp. 365-380, 2002.

[62] X. Xie, Z. Huang, and J.-S. Wang, "The impact of urban street layout on local atmospheric environment," Building and Environment, vol. 41, no. 10, pp. 1352-1363, 2006.

[63] X.-X. Li, R. E. Britter, L. K. Norford, T.-Y. Koh, and D. Entekhabi, "Flow and pollutant transport in urban street canyons of different aspect ratios with ground heating: largeeddy simulation," Boundary-Layer Meteorology, vol. 142, no. 2, pp. 289-304, 2012.

[64] A. W. M. Yazid, N. A. C. Sidik, S. M. Salim, and N. H. M. Yusoff, "Numerical prediction of air flow within street canyons based on different two-equation $k$ - $\varepsilon$ models," IOP Conference Series: Materials Science and Engineering, vol. 50, article 012012, 2013.

[65] L. J. Hunter, G. T. Johnson, and I. D. Watson, "An investigation of three-dimensional characteristics of flow regimes within the urban canyon," Atmospheric Environment Part B Urban Atmosphere, vol. 26, no. 4, pp. 425-432, 1992.

[66] C.-H. Liu, D. Y. C. Leung, and M. C. Barth, "On the prediction of air and pollutant exchange rates in street canyons of different aspect ratios using large-eddy simulation," Atmospheric Environment, vol. 39, no. 38, pp. 1567-1574, 2005.

[67] M. G. Badas, S. Ferrari, M. Garau, and G. Querzoli, "On the effect of gable roof on natural ventilation in two-dimensional urban canyons," Journal of Wind Engineering and Industrial Aerodynamic, vol. 162, pp. 24-34, 2017.

[68] J. J. Baik, R. S. Park, H. Y. Chun, and J. J. Kim, "A laboratory model of urban street-canyon flows," Journal of Applied Meteorology, vol. 39, no. 9, pp. 1592-1600, 2000.

[69] W. C. Cheng and C.-H. Liu, "Large-eddy simulation of flow and pollutant transports in and above two-dimensional idealised street canyons," Boundary-Layer Meteorology, vol. 139, no. 3, pp. 411-437, 2011.

[70] C. S. B. Grimmond and T. R. Oke, "Aerodynamic properties of urban areas derived from analysis of urban surface form," Journal of Applied Meteorology, vol. 38, no. 9, pp. 1261-1292, 1999.

[71] S. J. Jeong and M. J. Andrews, "Application of the $k-\varepsilon$ turbulence model to the high Reynolds number skimming flow field of an urban street canyon," Atmospheric Environment, vol. 36, no. 7, pp. 1137-1145, 2002.

[72] X.-X. Li, C.-H. Liu, and D. Y. C. Leung, "Large-eddy simulation of flow and pollutant dispersion in high-aspect-ratio urban street canyons with wall model," Boundary-Layer Meteorology, vol. 129, no. 2, pp. 249-268, 2008.

[73] M. Scungio, F. Arpino, L. Stabile, and G. Buonanno, "Numerical simulation of ultrafine particle dispersion in urban street canyons with the Spalart-Allmaras turbulence model," Aerosol and Air Quality Research, vol. 13, pp. 1423-1437, 2013.

[74] V. D. Assimakopoulos, H. M. ApSimon, and N. Moussiopoulos, "A numerical study of atmospheric pollutant dispersion in different two-dimensional street canyon configurations," Atmospheric Environment, vol. 37, no. 29, pp. 4037-4049, 2003. 
[75] X. Xie, Z. Huang, and J.-S. Wang, "Impact of building configuration on air quality in street canyon," Atmospheric Environment, vol. 39, no. 25, pp. 4519-4530, 2005.

[76] H. Zhang, T. Xu, Y. Wang, Y. Zong, S. Li, and H. Tang, "Study on the influence of meteorological conditions and the street side buildings on the pollutant dispersion in the street canyon," Building Simulation, vol. 9, no. 6, pp. 717-727, 2016.

[77] Y. Miao, S. Liu, T. Zheng, S. Wang, and Y. Li, "Numerical study of traffic pollutant dispersion within different street canyon configurations," Advances in Meteorology, vol. 2014, Article ID 458671, 14 pages, 2014.

[78] M. Princevac, J.-J. Baik, X. Li, H. Pan, and S. B. Park, "Lateral channeling within rectangular arrays of cubical obstacles," Journal of Wind Engineering and Industrial Aerodynamics, vol. 98, no. 8-9, pp. 377-385, 2010.

[79] J. Hang, Q. Wang, X. Chen et al., "City breathability in medium density urban-like geometries evaluated through the pollutant transport rate and the net escape velocity," Building and Environment, vol. 94, pp. 166-182, 2015.

[80] S. Kenjereš, S. de Wildt, and T. Busking, "Capturing transient effects in turbulent flows over complex urban areas with passive pollutants," International Journal of Heat and Fluid Flow, vol. 51, pp. 120-137, 2015. 

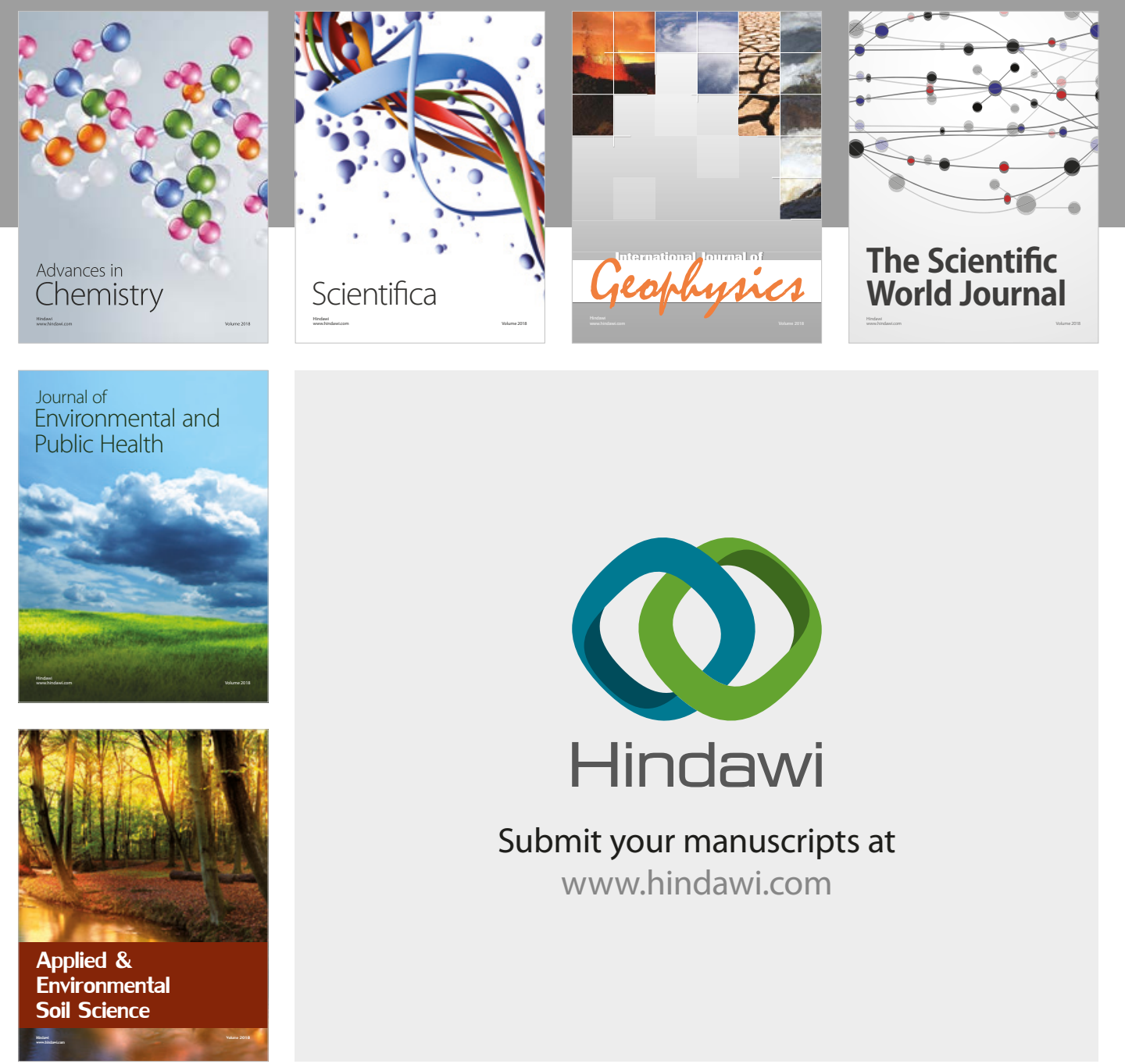

The Scientific

\section{World Journal}
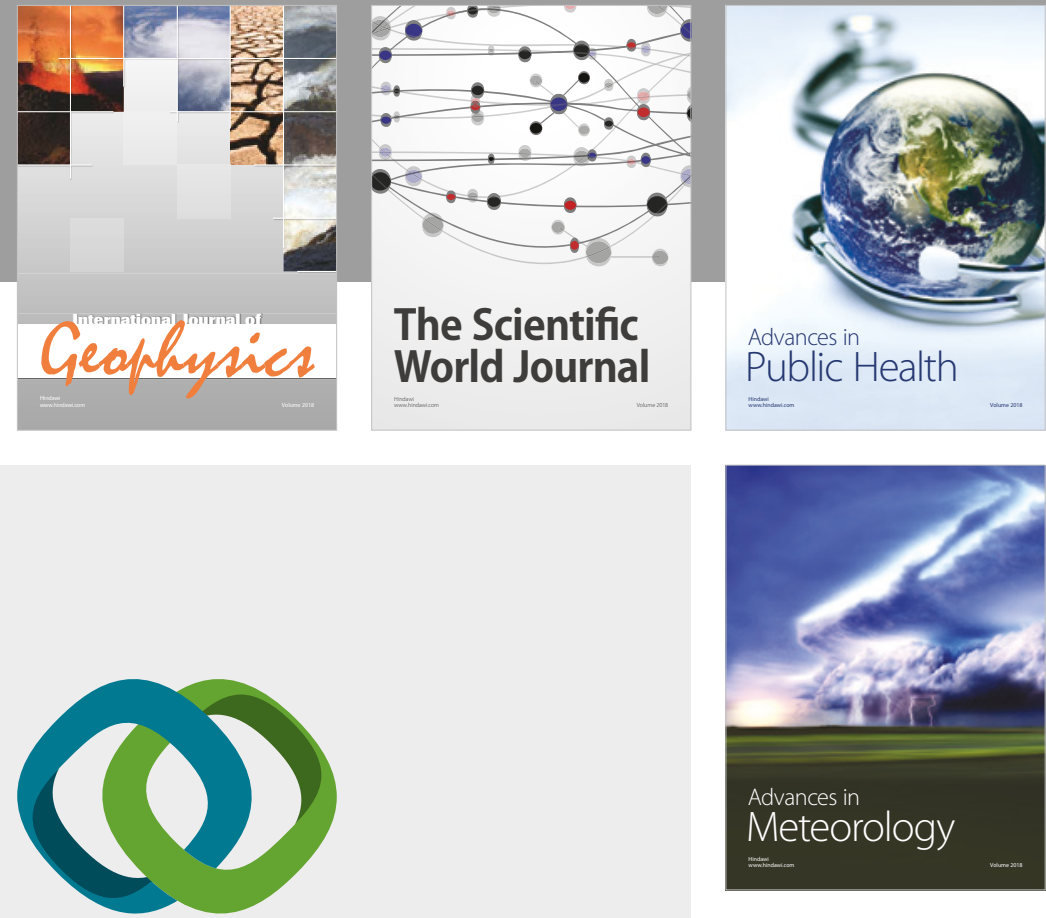

Advan

Public Health

\section{Hindawi}

Submit your manuscripts at

www.hindawi.com
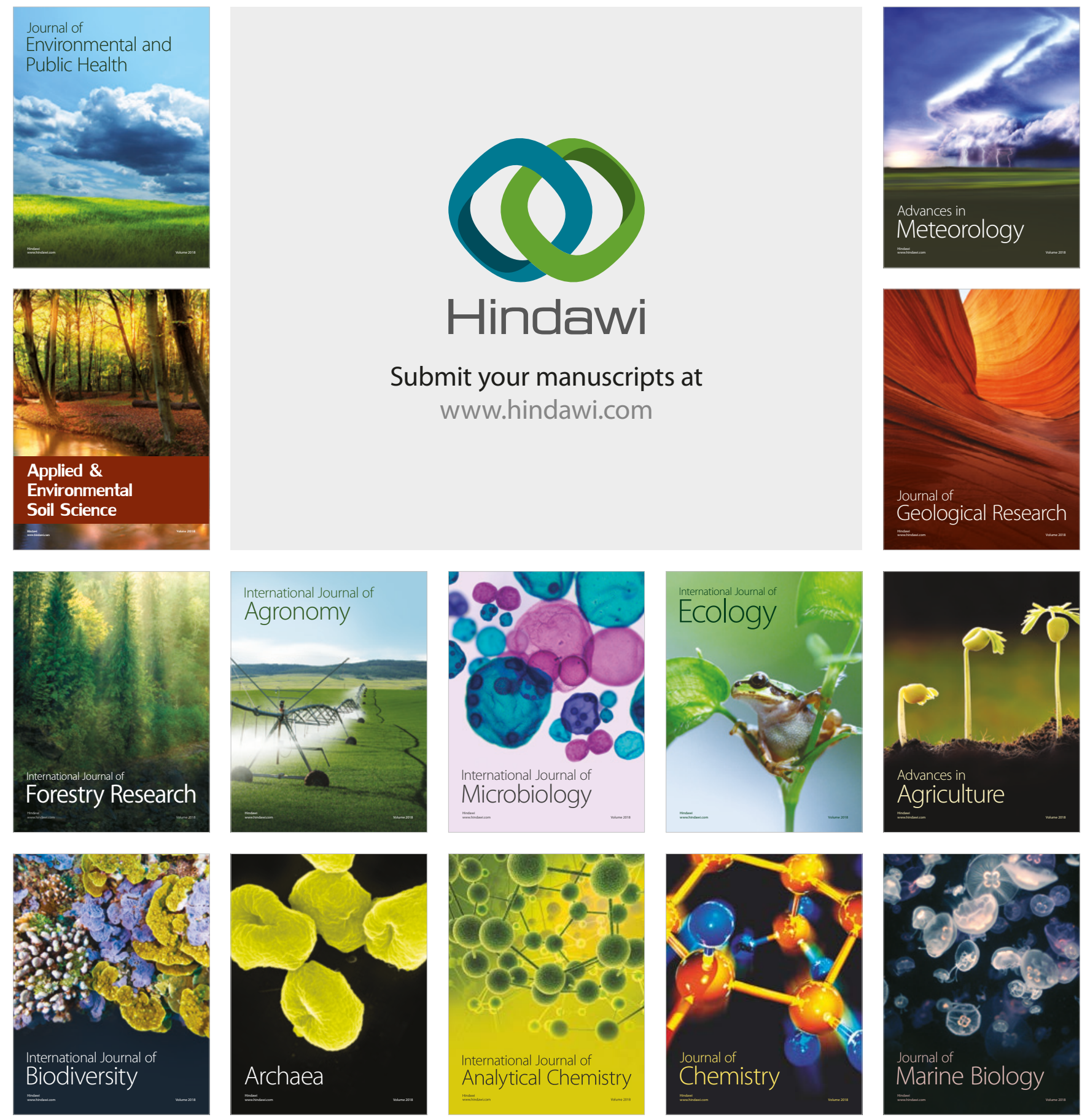